
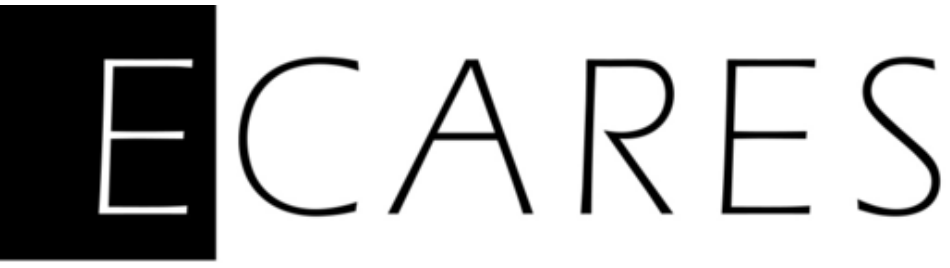

\title{
Pecking Order and Core-Periphery in International Trade
}

Karolien De Bruyne

KU Leuven

Glenn Magerman

SBS-EM, ECARES, Université libre de Bruxelles

Jan Van Hove

KU Leuven \& KBC Group

January 2019

ECARES working paper 2019-06

ECARES

ULB - CP $114 / 04$

50, F.D. Roosevelt Ave., B-1050 Brussels BELGIUM

www.ecares.org 


\title{
Pecking Order and Core-Periphery in International Trade*
}

\author{
Glenn Magerman, ECARES, ULB \\ Karolien De Bruyne, KU Leuven \\ Jan Van Hove, KU Leuven and KBC Group
}

October 2018

\begin{abstract}
This paper analyzes the impact of market size and trade costs on bilateral trade flows. A multi-country trade model with firm-level heterogeneity in productivities and countries' market potential provides a simple micro foundation for the link between these variables. In the model, market size and trade costs jointly determine a country-specific pecking order of exporters serving their destination countries. In a hypothetical setting where bilateral trade costs are homogeneous across country pairs, market size then implies a common ranking of exporters among destination countries. This leads to a unique core-periphery structure of the world trade network. Relaxing the assumption of homogeneous trade costs, we illustrate the impact of market size and trade costs on bilateral trade flows and its margins in a simple gravity-like setting. Using an instrumental variables approach, we find that both market size and trade costs (measured through the network position of countries) have a significant impact on bilateral exports: countries in the core bilaterally trade more with other countries in the core than with peripheral countries, conditional on typical observables.
\end{abstract}

Keywords: International Trade, Pecking Order, Core-Periphery, Market Potential.

JEL Codes: D85, F1, L1.

*E-mail: glenn.magerman@ulb.ac.be. Glenn Magerman gratefully acknowledges the financial support of Fulbright USA, Methusalem funding at VIVES/KU Leuven, the PhD Research Fellowship at KU Leuven, the National Bank of Belgium Sponsorship program 2014, the Otlet-La Fontaine scholarship, the Centre for Irish Studies at KU Leuven and the KU Leuven Junior Mobility Program. 


\section{Introduction}

The world trade network is characterized by a core-periphery structure (e.g. Fagiolo et al. (2010), De Benedictis and Tajoli (2011)). In this setting, a core of 'rich' countries trades heavily among themselves, while 'poor' peripheral countries predominantly trade with countries in the core. Further integration could therefore be more beneficial for the well-connected core countries than for the peripheral countries, increasing inequality between both. In this paper, we contribute to the important discussion on integration and inequality. Using a model of heterogeneous firms, we provide micro foundations for the observed core-periphery structure by studying the impact of market size and trade costs on trade flows. We show that firm-level productivity and destination countries' market potential drive the network structure of trade, resulting in a core-periphery network structure of trade flows in equilibrium, generated by a specific pecking order of firms exporting to their destinations.

It is well-documented that only a small fraction of firms export and that there is a large amount of heterogeneity across these exporters in terms of productivity, the number of products exported and the number of destinations served (e.g. Bernard et al. (2007)). In this paper, we explore this heterogeneity of exporters across products and destinations through the use of simple network statistics that capture these margins. We show that differences in firm productivity and destination market potential (Redding and Venables (2004)) are consistent with a strict pecking order of exporters serving their destinations in theory and provide evidence for this in the data. This pecking order represents a hierarchical list that exporters follow when choosing destinations: if a firm in country $i$ exports to the $j+1^{\text {th }}$ largest market, this firm also exports to the $j^{\text {th }}$ largest market. In other words, firms within a country follow the same pecking order when serving export destinations. Assuming homogeneous trade costs, one observes a common ranking of exporters among destination countries, thus leading to a unique core-periphery structure of exports. We subsequently take our model to the data and test for the existence of (i) a countryspecific pecking order of exporters serving their destination countries and (ii) a common ranking of exporters among destination countries implying a core-periphery structure in the world trade network.

We first present three stylized facts, pointing to a pecking order of exporters and a coreperiphery structure of international trade in actual trade data. Fact 1 shows that larger countries export to more destinations (i.e. they have a higher out-degree) and also import from more 
sources (i.e. higher in-degree). While simple, this fact establishes a strong role for the network structure of trade through zero-trade flows. Fact 2 shows evidence for the core-periphery structure of trade through a negative relationship between its out-degree and the fraction of destinations of a country that also trade among themselves (defined as the directed clustering coefficient). Jointly, facts 1 and 2 establish which countries are in the core and which are in the periphery: countries with a high out-degree/in-degree and a low clustering coefficient are in the core, while countries with a low out-degree/in-degree and a high clustering coefficient are in the periphery. Turning to product-level information, fact 3 shows that more connected countries also export a larger product variety, after controlling for exporter GDP. Moreover, all countries export the majority of their products to a few destinations, generating a very skewed distribution of the number of products exported by destination, consistent with a pecking order mechanism.

Next, we describe a multi-country general equilibrium model following Arkolakis et al. (2008), in which firm-level productivity differences establish the pecking order of exporters in country $i$ to all destinations $j$. Three mechanisms jointly determine the pecking order of trade. First, firms select into exporting if their productivity is sufficiently high to cover the fixed costs of exporting, while less productive firms only serve the domestic market. Second, more productive firms serve more destinations, defined by country-pair specific cutoff productivities that are increasing in trade costs. Third, some destinations are naturally more attractive for exporters, defined by a higher market potential. These three mechanisms imply a strict pecking order of exporters, jointly determined by heterogeneous trade costs and market size. Disentangling the effect of both variables - by shutting down heterogeneity in bilateral trade costs - we find that market size implies a common ranking of exports among destination countries thus leading to a unique core-periphery structure in global trade flows. Finally, we relax the assumption of homogeneous trade costs by allowing trade costs to differ bilaterally and as such illustrate that market size and bilateral trade costs have a strong and significant impact on bilateral trade: countries in the core trade more among themselves than with countries in the periphery.

We test for the existence of a pecking order using product-level export flows across all countries in the world. ${ }^{1}$ We evaluate the pecking order by comparing the observed hierarchy to a random matching procedure, following the methodology of Eaton et al. (2011). While

\footnotetext{
1 We assume that firms are unique single-product producers. This allows us to use the typical firm-level framework and match this to product flows we observe in the data. We acknowledge a large role for multi-product firms in international trade and ideally we would use firm-product level data for all countries in the world.
} 
the pecking order is not strict in the data (due to non-separability of bilateral trade costs and market potential or due to firm-specific demand shocks), there is evidence in favor of a pecking order of exporters. For instance, for the USA, we observe a strict pecking order for $45 \%$ of exported products to its top 10 destinations, much larger than when this pecking order would be randomly generated (17\%). We show that this finding also holds for other countries across the whole distribution of out-degrees: $92 \%$ of exporting countries share the same top ten destinations in the data, against a random matching probability of $68 \%$.

We then relax the assumption of homogeneous trade costs and evaluate the impact of the position of countries in the network (core or periphery) on bilateral trade flows in a simple gravity-like setting, deploying an instrumental variables (IV) approach. Endogeneity stems from the observation that trade flows and the network structure of trade are simultaneously determined in the model. Similar to Berry et al. (1995), we use characteristics of other countries to instrument the network variables of degrees and clustering. The network position of countries matters in explaining bilateral trade flows: a $1 \%$ increase in the number of destinations a country serves, is related to a $0.7 \%$ increase in the value of aggregate flows to any given destination on average, conditional on covariates. A $1 \%$ increase in the number of countries a country sources from, is related to a $0.8 \%$ increase in bilateral export values. However, the in-degree effect turns insignificant when applying the instrumental approach. Finally, a 1\% increase in the directed clustering coefficient is related to a $0.8 \%$ decrease on average per export flow. Splitting up trade flows into extensive and intensive margins, we find that the effect of the network statistics predominantly covers the extensive margin, consistent with the model. These findings confirm the intuition that countries with more destinations/sources and lower clustering coefficients are in the core of the world trade network and that all other things equal, these countries export more to any given destination.

This paper is related to two strands of literature. First, recent papers have pointed to a pecking order in international trade (e.g. Chan and Manova (2015)). Most of these papers use detailed export data at the firm level for a particular country (e.g. Eaton et al. (2011) for France, Bernard et al. (2016) for Norway, or Antràs et al. (2016) for the US). This allows the authors to establish the pecking order of destinations for a country's firms. Other papers also implicitly generate pecking orders (e.g. Yeaple (2009) in the light of foreign direct investment). These papers provide evidence for a pecking order of trade, but generally conclude that the ordering is not strict. Potential sources for this strict ordering to break down are the existence of demand 
shocks (Eaton et al. (2011)), or the failure of market potential to dominate bilateral trade costs (Helpman et al. (2008)). We add to this literature by illustrating that under homogeneous trade costs, market size alone implies a common ranking of exporters among destination countries. Finally, assuming trade costs to be heterogeneous we are able to better explain bilateral trade flows. Furthermore, using cross-country data, we can test both the (i) the country-specific pecking order of exporters serving their destination countries and (ii) the common ranking of exporters among destination countries.

Second, this paper relates to quantitative models of international trade and the gravity model (see Costinot and Rodríguez-Clare (2014) and Head and Mayer (2014) for excellent surveys). Many general equilibrium models derive a gravity equation allowing for counterfactual or datadriven trade policy analysis. Equilibrium price indices (or "multilateral resistance terms") are then the source of third-countries' impacts on bilateral trade flows on the intensive margin (e.g. Anderson and van Wincoop (2003)) or on the extensive margin (e.g. Eaton and Kortum (2002)). Helpman et al. (2008) allow for firm heterogeneity in this type of setting, generating structural zero export flows in a multi-country setting. Unfortunately, their empirical method is not widely implemented, due to potential convergence problems of a non-linear estimation procedure. Conversely, Santos Silva and Tenreyro (2006) allow for easy estimation of the gravity model in the presence of zero flows, but do not provide a structural model that generates these structural zeros. We present a simple model that generates pecking and zero flows and which can subsequently be estimated using straightforward techniques.

\section{Empirical evidence}

In this section, we provide empirical evidence that (i) a country-specific pecking order of exporters serving their destination countries exists and (ii) the world trade network is characterized by a core-periphery structure. Moreover, we dig deeper in the intuitive relationship between a country-specific pecking order structure on the one hand and a world-wide core periphery structure on the other hand. We can derive 3 empirical facts from the data:

\section{Fact 1 - Larger countries export to more destinations and import from more sources.}

Figure 1 shows the log-linear relationship between the GDP of a country and its number of export destinations and import sources for the year 2005 (data are described in Appendix A). Clearly, bigger countries export to more destinations and they import from more sources: a $1 \%$ increase 
in GDP of the exporter relates to a 0.19 increase in the number of destinations it serves on average; similarly a $1 \%$ increase in GDP of the importer relates to a 0.15 increase in the number of countries it imports from on average. From now on, we refer to the number of destinations country $i$ has at time $t$, as the out-degree of country $i, d_{i t}^{\text {out }}$. Formally, $d_{i t}^{\text {out }}=\sum_{j} T_{i j t}$, where $T_{i j t}$ is an indicator function equal to 1 if $i$ exports to $j$ at time $t$. Similarly, we denote the number of sources country $j$ has at time $t$, as the in-degree of country $j$, so that $d_{j t}^{i n}=\sum_{i} T_{i j t}$.

As a robustness test, as well as a motivation for the basic set-up of our model in the next section, we use additional proxies for productivity and market potential. We use GDP per capita as a simple proxy for country productivity of the exporter and for market potential of the importer. We also control for median geographical distance by exporters to each destination and similarly by importers from each source. All results are extremely robust to these alternative proxies (additional results in Appendix B).
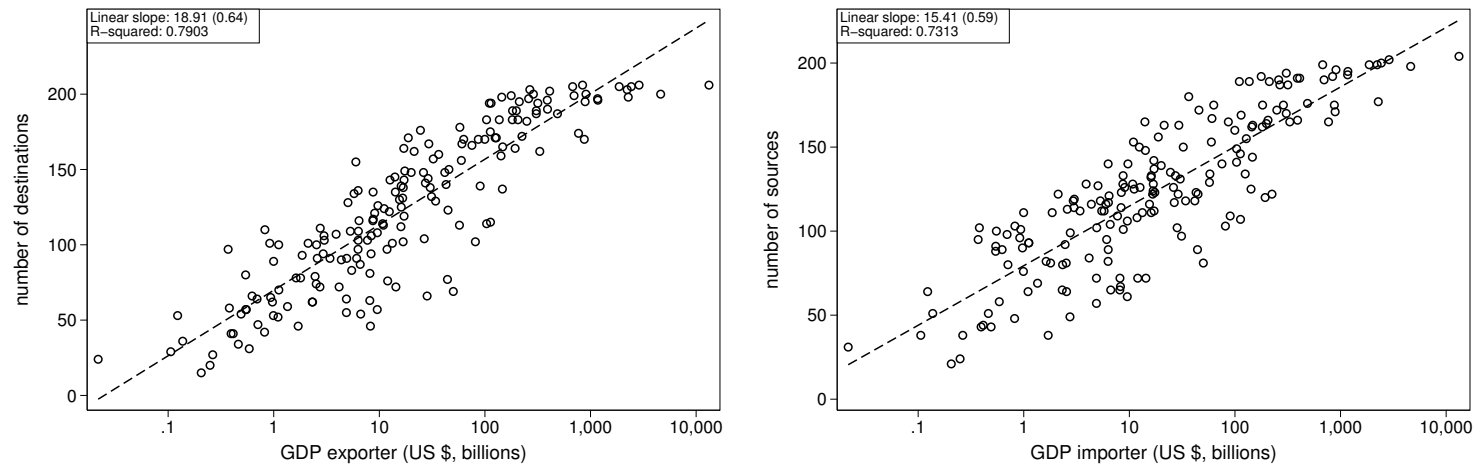

Notes: Each circle represents the GDP of a country and the number of its export destinations (left) and import sources (right) in 2005. The dotted line represents a linear regression of degrees regressed on the $\log$ of GDP. Regression results are presented in the top left box of each panel. Robust standard errors of the linear fit in parentheses; correlations are significant at the $0.1 \%$ level.

Figure 1: Market size and trading partners (2005).

Fact 2 - There is a negative correlation between degrees and clustering. Countries with a low out-degree tend to export to countries with a high in-degree, and countries with a high out-degree tend to export both to high and low in-degree countries. We measure this by relating $d_{i t}^{\text {out }}$ of $i$ to the directed clustering coefficient $C_{i t}^{\text {out }}$, a measure of how concentrated trade flows are between $i$ and all of its destinations at time $t$ : given that $i$ exports to $j$ and $k$ simultaneously, $C_{i t}^{\text {out }}$ measures the fraction of partners of $i$ that also trade among themselves, i.e. $j$ exports to $k$ and/or $k$ exports to $j^{2}{ }^{2}$ There is a negative correlation between $d_{i t}^{\text {out }}$ and $C_{i t}^{\text {out }}$

2 Technically, we follow the definition of the directed out-clustering coefficient as in Fagiolo (2007): $C_{i t}^{\text {out }}=$ $\left(A^{2} A^{T}\right)_{i i} /\left(d_{i t}^{\text {out }}\left(d_{i t}^{\text {out }}-1\right)\right)$, where $A$ is the adjacency matrix of country level trade flows with entries $a_{i j}=1$ if 
as shown in Figure 2: a unit increase in $d_{i t}^{\text {out }}$ is related to a decrease of 0.002 in the clustering coefficient on average. This effect is not small, as $C_{i t}^{\text {out }}$ only ranges between .55 and 1 in the data. Countries with high $d_{i t}^{\text {out }}$ are export hubs (i.e. their out-degree is proportional to the size of the network) exporting to many destinations, while these destinations are on average less connected among each other. This finding is also highly robust when controlling for exporter GDP (results in Appendix B).

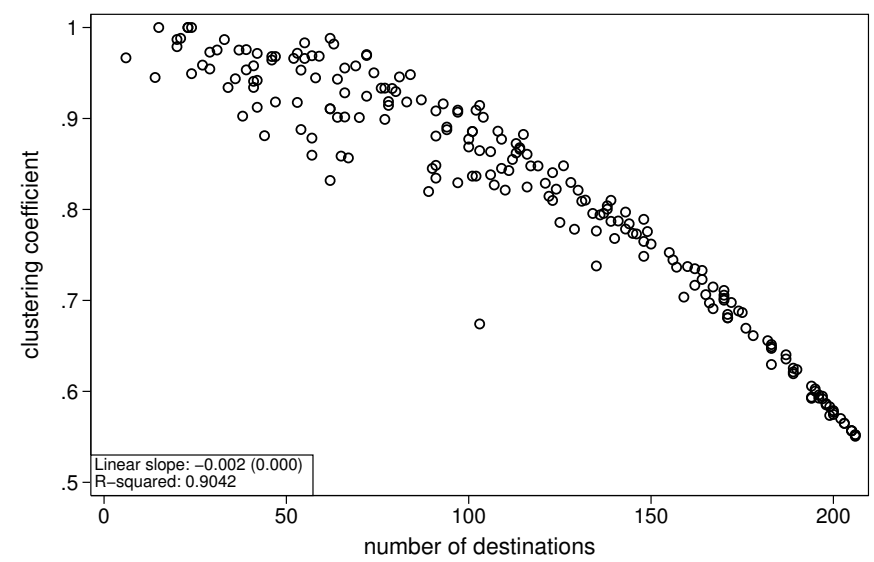

Notes: Each circle represents the out-degree of a country $d_{i t}^{\text {out }}$ and its clustering coefficient $C_{i t}^{\text {out }}$ in 2005. Regression results are presented in the lower left box. Robust standard errors of the linear fit in parentheses; correlation is significant at the $0.1 \%$ level.

Figure 2: Degrees versus clustering (2005).

Fact 3 - More connected countries export a larger product variety. Panel (a) in Figure 3 shows the distribution of the number of products (at the 6-digit level of the Harmonized System) shipped per yearly export flow for the year 2005. This distribution is heavily skewed: the median number of products exported from $i$ to $j$ is only 18, while 2,800 products or more are shipped at the 99th percentile, with a maximum of 4,731 products exported from France to Belgium-Luxembourg in 2005. Finally, panel (b) in Figure 3 shows the relation between the number of destinations for each country in 2005 and the mean number of products exported by that country to every destination. There is a clear log-linear relationship between out-degree and the diversity of exports of a country: a unit increase of export destinations is related to an increase of $3 \%$ new products exported by that country on average per destination.

$i$ exports to $j$ and 0 otherwise. $A^{T}$ is the transpose of $A$ and $(\cdot)_{i i}$ is the $i i$-th element of $(\cdot)$. The numerator calculates the actual number of closed triads emanating from $i$, while the denominator defines the potential number of triads emanating from $i$. Naturally, $C_{i}^{\text {out }} \in(0,1)$. As an alternative measure, Bernard et al. (2016) use the related concept of degree assortativity to correlate the out-degree of an exporter with the mean in-degree of its importers at the firm level. 
A robustness check with the median number of products per destination shows very similar results. Additionally, more connected countries are also larger, but the linear relationship holds after accounting for exporter GDP: the estimated coefficient drops from 0.03 to 0.02 while remaining highly significant. Finally, we also consider a bilateral variant of product variety and regress the log of the number of products exported per destination on $d_{i t}^{\text {out }}$, controlling for GDP of the exporter and geographical distance. Again, all results are highly robust to these alternative specifications (results in Appendix B).

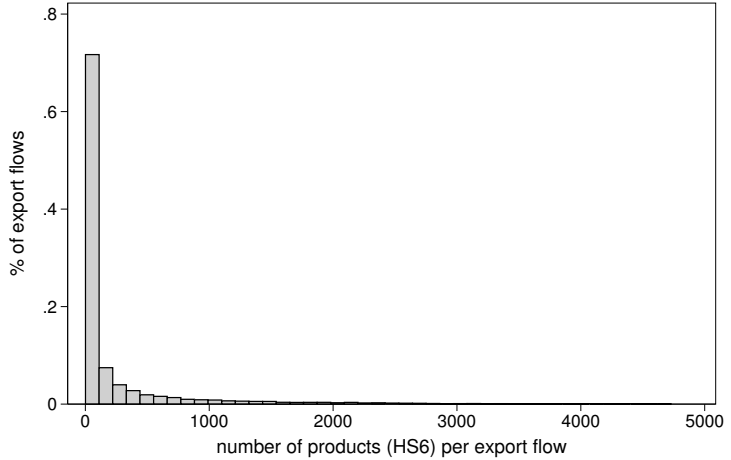

(a) Distribution of products (2005).

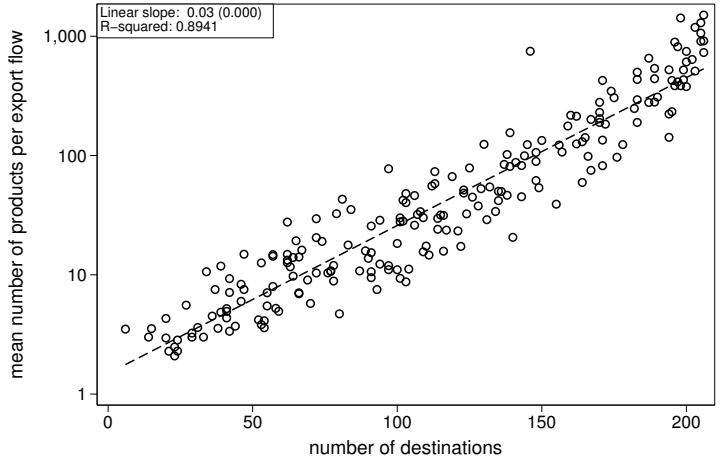

(b) Destinations and products (2005).

Notes: Panel (a) shows the distribution of the number of products per export pair in 2005. Panel (b) shows the mean number of products exported by out-degree. Linear regression results are presented in the top left corner of panel (b). Robust standard errors of the linear fit in parentheses; correlations are significant at the $0.1 \%$ level.

Figure 3: Trade flows, market size and product variety.

Facts 1 and 2 jointly determine the core-periphery structure of international trade that we observe in reality: a set of countries in the core trade among themselves and with countries in the periphery, while peripheral countries trade mostly with countries in the core. Fact 1 establishes a link between the economic size of an exporter and its number of trading partners: a low GDP country will have both a low out-degree and a low in-degree and conversely so for high GDP countries. Fact 2 shows the disassortative nature of these trade flows.

Two networks with the same degree distribution but with a different clustering distribution can generate very different network structures. The simplest way to see we need both fact 1 and 2 to generate a core-periphery structure is through a simple thought experiment. Consider the following two extremes, where we enforce the assortative/disassortative matching principle and let the degree distribution adjust to this matching, while setting $d_{i t}^{\text {out }}=d_{i t}^{\text {in }}$ for simplicity: ${ }^{3}$

3 Letting the degree distribution settle from the matching principle rules out that there is for example only one country with $d_{i t}^{\text {out }}=10$, which might not be able to connect following the perfect matching principles enforced in this example. 
(i) perfect assortative matching, where countries only export to countries that have the same degree (i.e. a country with $d_{i t}^{\text {out }}=1$ exports to another country that has $d_{j t}^{\text {in }}=1$, and so on for all degrees); and (ii) perfect disassortative matching, where the country with the lowest $d_{i t}^{\text {out }}$ exports to the countries with the highest $d_{j t}^{i n}$.

In case (i), there are cliques (completely connected subgraphs) of countries with the same degree, trading with all other countries in the same clique and none of the others, resulting in several disconnected components in the network. This leads to $C_{i t}^{\text {out }}=1$ for all $i$, independent of the size of the clique to which they belong. In an even more constrained case where every node also has the same degree, this collapses to a complete network in which every country exports to every other country in the network. This is the case for models of international trade that exhibit monopolistic competition and no fixed costs of exporting (e.g. Anderson and van Wincoop (2003)) or models with fixed costs in which countries are completely symmetric (Krugman (1980), Melitz (2003)). ${ }^{4}$

Case (ii) with perfect disassortative matching results in a star network, in which one country (the center) exports to all other countries and all other countries only export to the center. The center then has $d_{i t}^{\text {out }}=\max \left\{d_{i t}^{\text {out }}\right\}$; all other countries have $d_{i t}^{\text {out }}=1$ and $C_{i t}^{\text {out }}=0$ for all countries in the network, as none of the export destinations of the center export to each other. In reality however, we observe that $C_{i t}^{\text {out }}$ is decreasing in $d_{i t}^{\text {out }}$. This indicates that the world trade network is in-between these extremes, as $C_{i t}^{\text {out }}$ is not independent of $d_{i t}^{\text {out }}$. There are several hubs in the world (with a high $d_{i t}^{\text {out }}$ ) and we can think of each of those as the center of a star $\left(C_{i t}^{\text {out }} \rightarrow 0\right)$. These stars will also be connected to each other, leading to a core-periphery structure in which these hubs form the core and the less connected countries the periphery, raising $C_{i t}^{\text {out }}$ again for these hubs. At the same time, the peripheral countries export to some hubs simultaneously, generating a high $C_{i t}^{\text {out }}$ for these peripheral countries.

Given the skewed distribution of varieties per exporter (Fact 3), a particular structure of international trade arises. The next step is then to identify this ranking structure. We already have some intuition that firms inside a country follow a hierarchical market strategy, as the most popular destinations get most variety from one particular exporter, while variety decreases in destinations down the ranking - leading to a country-specific pecking order. If all other countries follow the same ranking as country $i$, i.e. destinations can be ranked in terms of attractiveness

\footnotetext{
4 In symmetric models with fixed costs of exporting, there is the additional equilibrium of an empty network (i.e. global autarky) whenever no firm in $i$ can overcome the cutoff productivity to export.
} 
by assuming trade costs to be homogeneous, market size alone implies a common ranking of exporters among destination countries. This leads to a core-periphery structure in global trade flows. The model we develop in the next Section, allows us to derive a testable hypothesis for this pecking order and global core-periphery structure to hold, which we subsequently test in the data.

Finally, Figure 4 shows a graphical representation of a toy network that allows us to both illustrate as well as link the country-specific pecking order and the global core-periphery concept. Exporting firms within a particular country are labeled $i_{1}, i_{2}, \ldots$ and ranked in terms of productivity. Similarly, importing countries are labeled $j_{1}, j_{2}, \ldots$ and ranked in terms of market potential (proxied by $d_{j t}^{i n}$ ). Arrows represent export flows from $i$ to $j$. Firm $i_{1}$ exports to all destinations $j$, firm $i_{2}$ exports to $j_{1}, j_{2}$ and $j_{3}$ etc. thus reflecting a pecking order where exporters first export to the most popular destination $j_{1}$ and go down the list of destinations. Market size and heterogeneous trade costs (both measured by the market potential) interact and as such jointly determine a country-specific pecking order of exporters. By considering all exporting firms within one exporting country, we are therefore not able to disentangle the trade cost effect from the market size effect. If we control for trade costs - assuming them to be homogeneous - market potential only reflects market size and this market size automatically implies a global ranking of exports among destination countries. One can see this by re-interpreting Figure 4 as follows: exporting countries are now labeled $i_{1}, i_{2}, \ldots$. Country $i_{1}$ is then an export hub, exporting to all destinations, while country $j_{1}$ is the most popular destination and both are in the core of the network. Conversely, $i_{4}$ and $j_{4}$ are peripheral exporters and importers respectively.

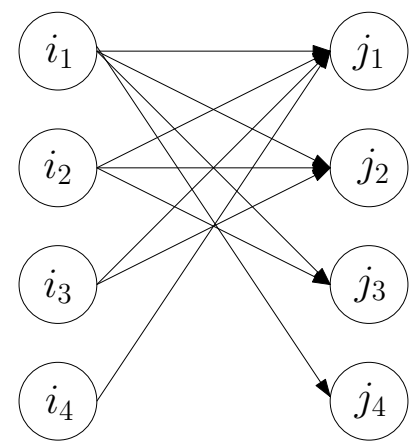

Notes: A toy network exhibiting pecking order and core-periphery structure. Exporting firms/countries are labeled $i_{1}, i_{2}, \ldots$; importing countries are labeled $j_{1}, j_{2}, \ldots$

Figure 4: Pecking order and core periphery example. 


\section{Model}

We present a static multi-country model of international trade with heterogeneous firms in terms of productivity facing fixed costs of exporting to their destination markets. The model largely follows Arkolakis et al. (2008), where we now let the exporting firms pay the fixed cost, in contrast to the fixed cost being paid by the importer in their model. Our model as such determines the impact of differences in productivity and market potential on trade patterns through a pecking order structure and a core-periphery network.

\subsection{Setup}

Demand There are $L_{j}$ identical consumers in country $j=\{1, \ldots, n\}$, who have constant elasticity of substitution (CES) preferences over a continuum of goods $\omega \in \Omega_{j}$, where $\Omega_{j}$ is the endogenous set of goods available for consumption in $j$, so that:

$$
U_{j}=\left[\int_{\omega \in \Omega_{j}} q_{j}(\omega)^{\rho} d \omega\right]^{1 / \rho}
$$

where $\sigma=\frac{1}{1-\rho}>1$ is the elasticity of substitution, common across goods. Residual demand for each good $\omega$ in country $j$ is then given by $q_{j}(\omega)=\frac{p_{j}(\omega)^{-\sigma}}{P_{j}^{1-\sigma}} Y_{j}$, where $p_{j}(\omega)$ is the price of good $\omega$ and the ideal price index is given by $P_{j}^{1-\sigma}=\int_{\omega \in \Omega_{j}} p_{j}(\omega)^{1-\sigma} d \omega$. Labor is the only factor of production and total expenditure is $Y_{j}=w_{j} L_{j}$ where $w_{j}$ is the wage in $j$. Model derivation is provided in Appendix C.

Supply There is one sector with differentiated goods, populated by a continuum of firms competing in monopolistic competition. In equilibrium, each firm chooses to produce a unique variety. Labor is paid in wages and is inelastically supplied in the aggregate as $L_{i}$. There is free entry and prior to entry, firms in country $i$ pay an exploration cost $f_{e}$ in terms of labor, which is sunk after payment. This entitles firms to draw their productivity level $\phi$ from a Pareto distributed cumulative distribution function $G(\phi) \equiv 1-\left(\frac{\phi_{\min }}{\phi}\right)^{\theta}$ with support $\left[\phi_{\min }, \infty\right)$, where $\phi \geq \phi_{\min }>0$ and we require $\theta>1$ for the distribution to have a finite mean. The shape parameter of the distribution is given by $\theta$, common across all countries and inversely related to the variability of the distribution: a higher $\theta$ leads to all firms being closer to $\phi_{\min }$. If a firm draws $\phi<\phi_{i i}^{*}$, where $\phi_{i i}^{*}$ is the endogenous productivity cutoff of serving its domestic market, the firm exits the market before producing. Alternatively, a firm will start producing domestically, 
facing fixed costs of production $f_{i}$ (also paid in labor) so that the cost of production in terms of labor $l_{i}$ is given by $l_{i}(\phi)=f_{i}+q_{i}(\phi) / \phi$. Note that $f_{i}$ is common across firms inside $i$ (e.g. red tape, institutions, infrastructure), while $\phi$ varies by firm through the realized draws. Given that firms in $i$ only differ in terms of productivity, we can uniquely map goods $\omega$ to $\phi$.

Equilibrium In order to export to $j$, firms face an additional fixed cost $f_{i j}$ of entering a particular market $j$, paid in labor (with $f_{i i} \equiv 0$ ) and also iceberg variable trade costs $\tau_{i j}$ (with $\left.\tau_{i i} \equiv 1\right)$. Fixed costs of exporting are assumed sufficiently large $\left(\phi_{i j}^{*}>\phi_{i i}^{*}\right.$ for all $\left.j \neq i\right)$ so that selection into exporting occurs. Moreover, $\phi_{i j}^{*}$ varies across country pairs. Demand for good $\phi$ produced in $i$ and consumed in $j$ is then given by $q_{i j}(\phi)=\frac{p_{i j}(\phi)^{-\sigma}}{P_{j}^{1-\sigma}} Y_{j}$ where $p_{i j}(\phi)$ denotes the price of $\phi$ in $j$ exported from $i$. Since firms in monopolistic competition facing CES preferences charge a constant markup, the optimal price and the optimal number of destinations are separate optimizations (Redding (2011), Chan and Manova (2015)). The firm's maximization problem then reduces to choosing the optimal price for each market separately so that:

$$
\pi_{i j}(\phi)=\max \left\{p_{i j}(\phi) q_{i j}(\phi)-q_{i j}(\phi) \frac{w_{i} \tau_{i j}}{\phi}-w_{i} f_{i j}, 0\right\}
$$

The price of good $\phi$, produced in $i$ and consumed in $j$ is then $p_{i j}(\phi)=\frac{w_{i} \tau_{i j}}{\rho \phi}$. Plugging back into profits and summing over all destinations $j$ to which firm $\phi$ exports:

$$
\pi_{i}(\phi)=\sum_{j: \phi \geq \phi_{i j}^{*}} \pi_{i j}(\phi)=\sum_{j: \phi \geq \phi_{i j}^{*}}\left[\left(\frac{\rho \phi P_{j}}{w_{i} \tau_{i j}}\right)^{\sigma-1} \frac{Y_{j}}{\sigma}-w_{i} f_{i j}\right]
$$

Firms only export to destinations $j$ for which productivity is sufficiently high to generate positive profits $\left(\phi \geq \phi_{i j}^{*}\right)$. The cutoff productivity $\phi_{i j}^{*}$ for firms in $i$ serving a particular destination $j$ is then given by the zero profit condition for the marginal firm under free entry:

$$
\phi_{i j}^{*}=\left[\frac{w_{i} f_{i j} \tau_{i j}^{\sigma-1}}{Y_{j} P_{j}^{\sigma-1}} \sigma\left(\frac{w_{i}}{\rho}\right)^{\sigma-1}\right]^{\frac{1}{\sigma-1}}
$$

Higher costs of exporting $\tau_{i j}$ and $f_{i j}$ lead to higher bilateral entry cutoffs, as do higher wages $w_{i}$. Larger markets in terms of $Y_{j}$ and higher price levels $P_{j}$ lower the cutoff $\phi_{i j}^{*}$. We define the market potential $M P_{i j}$ of a country $j$ for firms in $i$ as (following Redding and Venables (2004)): $M P_{i j} \equiv \frac{Y_{j} P_{j}^{\sigma-1}}{w_{i} f_{i j} \tau_{i j}^{\sigma-1}}$. Note that the entry cutoff $\phi_{i j}^{*}$ decreases in $M P_{i j}$ : the more attractive a destination is, the easier it is to export to that destination. It is now obvious that both 
productivity differences and market potential (i.e. market size and trade costs) influence the decision to export (and therefore trade flows). Under free entry, the price index $P_{i}$ and cutoff productivities $\phi_{i j}^{*}$ pin down the endogenous measure of firms $M_{i}$ as well:

$$
M_{i}=L_{i} \frac{\left(\phi_{i_{\min }} / \phi_{i i}^{*}\right)^{\theta}}{(1+\theta) f_{e}}
$$

All other things equal, larger countries $L_{i}$ have a larger mass of firms, and similarly so for countries with lower cutoff productivities $\phi_{i i}^{*}$.

Trade flows Using the conditional probability of successful exporting from $i$ to $j$, we can define the value of trade flows $X_{i j}$ in terms of an intensive and extensive margin:

$$
X_{i j}=\underbrace{T_{i j}\left(\frac{\phi_{i i}^{*}}{\phi_{i j}^{*}}\right)^{\theta} M_{i}}_{\text {ext. margin }} \underbrace{w_{i} f_{i j} \frac{\sigma \theta}{\theta-\sigma+1}}_{\text {int. margin }}
$$

where the extensive margin is the measure of firms of $i$ that export to $j$, conditional on entry in $i$ and $j$, while the intensive margin represents the average revenue per firm exporting from $i$ to $j{ }^{5} T_{i j}$ is an indicator function for the ex post probability of exporting for firms in $i$ to $j$ : $T_{i j}=1$ if $\phi_{i}^{\max } \geq \phi_{i j}^{*}$ and zero otherwise, where $\phi_{i}^{\max }$ is the productivity of the most productive firm in $i$. As in Melitz (2003), trade affects both cutoffs $\phi_{i i}^{*}$ and $\phi_{i j}^{*}$, leading to a reshuffling of firms serving both domestic and international markets. In addition, if no firm in $i$ overcomes the cutoff productivities for entry in $j$, there is zero trade from $i$ to $j$. Next, $\frac{\sigma-1}{\sigma \theta}$ is the share of labor spent to the fixed costs of entry, which would be the profit share in Chaney (2008) if consumers only owned shares of domestic firms. Finally, note that there is a clear demarcation of the effects of endogenous variables on each margin in this model: changes in $Y_{j}, w_{i}, f_{i j}, \tau_{i j}$ and $P_{j}$ all enter the extensive margin through $\phi_{i j}^{*}$. Conversely, the intensive margin only depends on $w_{i} f_{i j}$ and exogenous parameters. The (indirect) impact of productivity differences and market potential (directly) through pecking order and core-periphery - on bilateral trade flows is therefore mainly to be expected on the extensive margin. We will confirm this finding when we take our model to the data in Section $4 .^{6}$

\footnotetext{
${ }^{5}$ Note that $\left(\phi_{i i}^{*} / \phi_{i j}^{*}\right)^{\theta}$ is the ex post probability of exporting for firms in $i$ to $j$, affected by the shape of the distribution $\theta$, which governs competition intensity: a rise in $\theta$ leads to a drop in the probability of exporting as firms are closer to each other in terms of productivity. Hence, $\theta$ also affects the density of the network in this setup.

6 The intensive margin is independent of variable trade costs when productivities are distributed Pareto: higher variable trade costs reduce average export revenues per firm, while they also induce less productive firms to
} 
Next, a gravity equation can be derived from (6), using the equilibrium measure of firms in $i$, goods market clearing and cutoff productivities, so that:

$$
X_{i j}=Y_{i} Y_{j} \frac{T_{i j} w_{i} f_{i j}^{1-\theta /(\sigma-1)}\left(w_{i} \tau_{i j}\right)^{-\theta}}{\sum_{k \neq j: \phi_{k}^{m a x} \geq \phi_{k j}^{*}} Y_{k} w_{k} f_{k j}^{1-\theta /(\sigma-1)}\left(w_{k} \tau_{k j}\right)^{-\theta}}
$$

Note that (7) is very similar to the gravity equations in Eaton and Kortum (2002), Chaney (2008) and Arkolakis et al. (2008), where we explicitly denote the existence of zero trade flows: $T_{i j}=X_{i j}=0$ if no firm in $i$ is able to overcome the productivity thresholds for $j$. Additionally, we condition the denominator (the so-called multilateral resistance terms) on the set of active exporters from $k$ to $j$ so that exports from $i$ to $j$ are only affected by this set of active exporters. This is in contrast to models with only variable trade costs and an Armington assumption such as Anderson and van Wincoop (2003), exhibiting a complete network. In these models, the multilateral resistance terms are determined by all countries in the world. Moreover, the elasticity of fixed costs of exporting is exactly the same as in Chaney (2008) and Arkolakis et al. (2008): changes in trade flows due to changes in fixed costs of exporting are a function of the size distribution of firms, i.e. gravity is "distorted" due to the existence of fixed costs (which influences destinations' market potential) and firm heterogeneity.

\subsection{Illustration of the country-specific pecking order}

Recall from panel (a) in Figure 3 that the distribution of the number of products is heavily skewed. Furthermore, this skewness holds when we break flows down by exporter, as illustrated in Figure 5. We show results for the max, 75th, 50th and 25th percentiles in $d_{i t}^{\text {out }}$ in 2005 (USA, Tunisia, Mali and Aruba respectively). This illustrates that the skewness in Figure 3 is not driven by a few large countries exporting a lot of products to all of their destinations while most countries export only a small set of products, but all countries have a few top destinations where much more products are exported to, relative to the bulk of their export flows. This result is invariant to the number of destinations a country has.

The model predicts that all firms inside a country follow the same pecking order when serving export destinations. We evaluate this prediction against the data and use a methodology similar to Eaton et al. (2011), who evaluate French exporters at the firm level and how they penetrate foreign markets. Bernard et al. (2016) also use this methodology at a finer grained

exit that destination market, raising average export revenues per firm again. Under Pareto these effects exactly cancel out. 

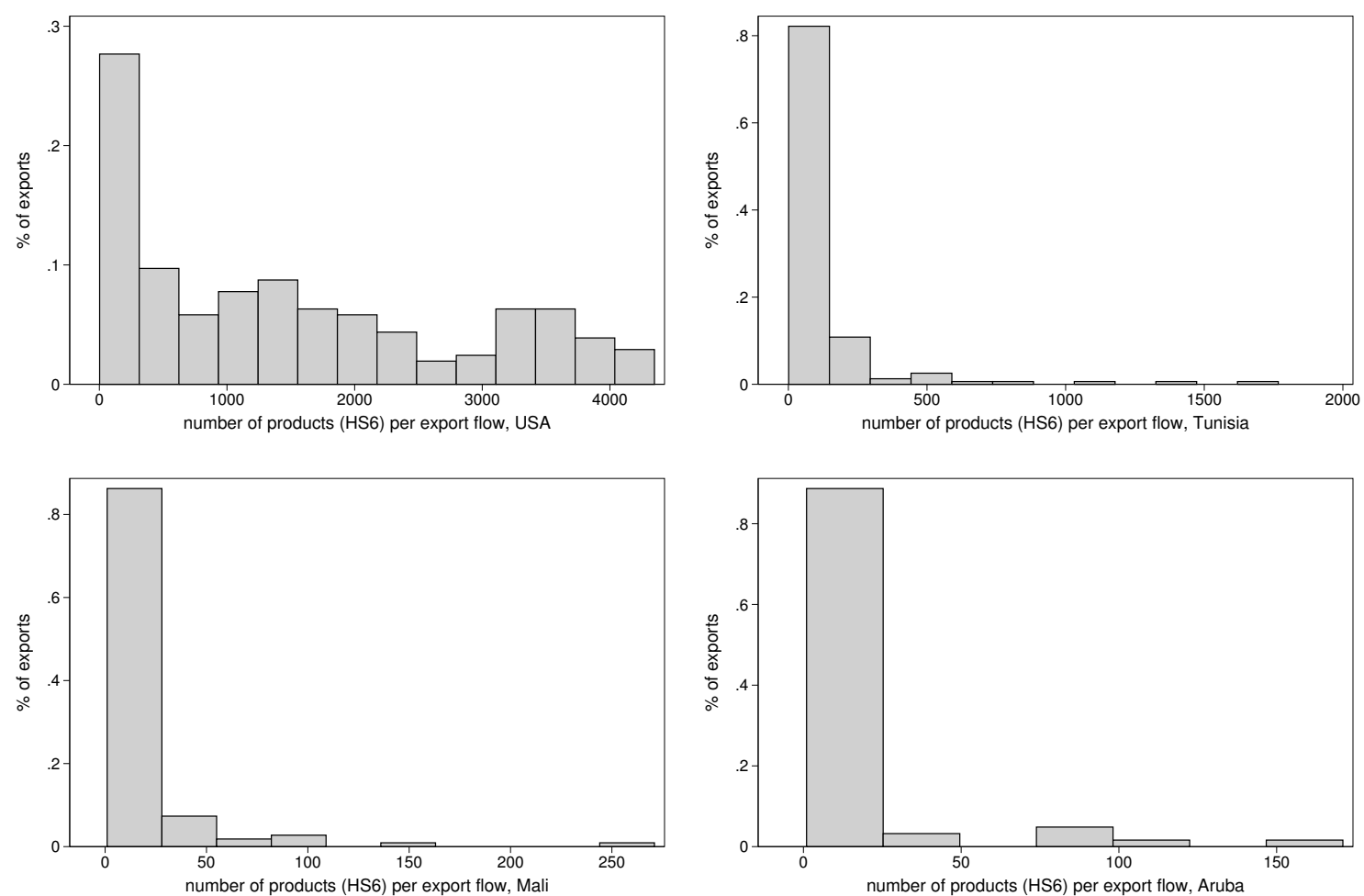

Notes: Panels show the distribution of the number of products per export pair in 2005, for USA (top left), Tunisia (top right), Mali (bottom left) and Aruba (bottom right).

Figure 5: Variety across exporters (2005).

level to evaluate the pecking order behavior of Norwegian exporters to the rest of the world, but now matched against firm counterparts in these destinations. We implement this exercise at a higher level by comparing exported products (rather than goods by firms) across countries. The empirical counterpart for the mass of exported variety from $i$ to $j, M_{i j}$, in our data is the HS6 product level, which we use to identify the pecking order patterns.

We show results in Table 1. The method is as follows: we rank destinations in terms of how many HS6 codes are exported by the USA $\left(n_{j}\right)$ to each destination $j\left(r_{j}\right)$ and consider only the top 10 destinations of the USA in terms of $n_{j}$. The bottom of the second column reports the total number of different products exported by the USA to the rest of the world in 2005, $n_{U S A}$. The third column shows the fraction of exported goods from the USA to destination $j$, $\rho_{r_{j}}=n_{j} / n_{U S A}$.

Then, if matching would be random, we calculate how many products $\left(n_{j}^{*}\right)$ would follow a strict pecking order in column 4. A strict pecking order under independence is simply given by the joint independent probabilities of a good being exported to a particular destination. For instance, the joint probability of a good to be exported to only the most popular destination 
and to none of the other top 10 destinations from a random matching procedure is given by $p_{1}=\rho_{1} \prod_{r=2}^{10}\left(1-\rho_{r}\right)$. The probability of a good to be exported to only the top 2 destinations is then $p_{2}=\rho_{1} \rho_{2} \prod_{r=3}^{10}\left(1-\rho_{r}\right)$, etc. The expected number of products exported to $j\left(n_{j}^{*}\right)$, conditional to being exported to only the top $r$ and to none of the other destinations, is then the joint probability times the number of goods exported by the USA in 2005 , or $p_{j} \times n_{U S A}$. Summing over the top 10 destinations gives the total expected number of products exported by the USA to its top 10 destinations following a strict pecking order under independence, $n_{U S A}^{*}=\sum_{j} n_{j}^{*}$. The ratio of products following a strict pecking order from random matching is then given by $\frac{n_{U S A}^{*}}{n_{U S A}}$ in the last cell of column 4 .

Finally, we compare this to the number of goods that follow a strict pecking order in the data in column 5: how many goods are exported from the USA to South Korea and to no other destinations in the top 10, to South Korea and the UK but nowhere else in the top 10 etc. We sum the observed number of products following this strict pecking order in the penultimate cell of the fifth column and again calculate the ratio. Comparing both ratios is then a simple indicator whether observing a strict pecking order in the data is more likely than a strict pecking order from random matching, given the number of products exported to each destination. The observed fraction of goods exported following a pecking order is thus between 0 and 1 , where 1 indicates a perfect strict pecking order. Since we compare to a random matching, if the observed fraction is larger than the random match, this indicates some degree of pecking order structure.

For example, USA exports a total of 5,072 different HS6 products in 2005, of which 4,349 to South-Korea or $86 \%$ of its exported product variety. A strict pecking order from a random matching procedure would then emerge for 0 products exported to South-Korea and none of the other 9 destinations, while we find in reality that 11 products are exported to South-Korea and none of the others in the top 10. Summing over this top 10, we find that random matching would lead to a strict pecking order of $17 \%$ of products, while we observe $45 \%$ in reality, supporting empirical evidence in favor of the pecking order from the model.

We repeat the exercise for the other three countries. However vastly different these countries might be in terms of economic development, distance to markets, the set of products they export and the countries they export to, in every case we find evidence in favor of the pecking order theory within countries. However, the pecking order hierarchy is far from strict, indicating that other mechanisms such as bilateral distance do dominate market potential in many instances. 


\begin{tabular}{|c|c|c|c|c|c|c|c|c|c|}
\hline \multicolumn{5}{|c|}{ Top 10 products USA } & \multicolumn{5}{|c|}{ Top 10 products Tunisia } \\
\hline$r_{j}$ & $n_{j}$ & $\rho_{r_{j}}$ & $n_{j}^{*}$ & data & $r_{j}$ & $n_{j}$ & $\rho_{r_{j}}$ & $n_{j}^{*}$ & data \\
\hline KOR & 4,349 & 0.86 & 0 & 11 & FRA & 1,767 & 0.58 & 151 & 302 \\
\hline GBR & 4,337 & 0.86 & 0 & 5 & ITA & 1,435 & 0.47 & 133 & 141 \\
\hline JPN & 4,207 & 0.83 & 0 & 5 & LBY & 1,106 & 0.36 & 75 & 30 \\
\hline AUS & 4,201 & 0.83 & 0 & 1 & DZA & 816 & 0.27 & 27 & 25 \\
\hline $\mathrm{CHN}$ & 4,054 & 0.80 & 1 & 5 & BLX & 661 & 0.22 & 8 & 6 \\
\hline FRA & 4,039 & 0.80 & 4 & 4 & ESP & 512 & 0.17 & 2 & 1 \\
\hline ITA & 4,010 & 0.79 & 14 & 7 & GBR & 493 & 0.16 & 0 & 2 \\
\hline CRI & 3,956 & 0.78 & 50 & 15 & MAR & 478 & 0.16 & 0 & 4 \\
\hline $\mathrm{COL}$ & 3,948 & 0.78 & 176 & 204 & GER & 471 & 0.15 & 0 & 2 \\
\hline $\mathrm{HKG}$ & 3,927 & 0.77 & 604 & 2032 & USA & 377 & 0.12 & 0 & 13 \\
\hline$n_{U S A}$ & 5,072 & $n_{U S A}^{*}$ & 850 & 2,289 & $n_{T U N}$ & 3,065 & $n_{T U N}^{*}$ & 397 & 526 \\
\hline ratio & & & 0.17 & 0.45 & ratio & & & 0.13 & 0.17 \\
\hline \multicolumn{5}{|c|}{ Top 10 products Mali } & \multicolumn{5}{|c|}{ Top 10 products Aruba } \\
\hline$r_{j}$ & $n_{j}$ & $\rho_{r_{j}}$ & $n_{j}^{*}$ & data & $r_{j}$ & $n_{j}$ & $\rho_{r_{j}}$ & $n_{j}^{*}$ & data \\
\hline FRA & 271 & 0.31 & 117 & 124 & $\mathrm{SAU}$ & 171 & 0.30 & 66 & 124 \\
\hline BFA & 144 & 0.16 & 23 & 62 & VEN & 109 & 0.19 & 15 & 62 \\
\hline AUS & 108 & 0.12 & 3 & 23 & NLD & 94 & 0.16 & 3 & 23 \\
\hline SEN & 98 & 0.11 & 0 & 12 & YEM & 92 & 0.16 & 1 & 12 \\
\hline USA & 95 & 0.11 & 0 & 5 & USA & 86 & 0.15 & 0 & 5 \\
\hline CIV & 63 & 0.07 & 0 & 4 & $\mathrm{COL}$ & 41 & 0.07 & 0 & 4 \\
\hline $\mathrm{ZAF}$ & 56 & 0.06 & 0 & 4 & MEX & 26 & 0.05 & 0 & 4 \\
\hline NER & 53 & 0.06 & 0 & 1 & GER & 21 & 0.04 & 0 & 1 \\
\hline GER & 45 & 0.05 & 0 & 5 & HND & 20 & 0.04 & 0 & 5 \\
\hline GIN & 43 & 0.05 & 0 & 2 & BRA & 18 & 0.03 & 0 & 2 \\
\hline \multirow{2}{*}{\multicolumn{2}{|c|}{$\begin{array}{cc}n_{M L I} & 889 \\
\text { ratio } & \\
\end{array}$}} & $n_{M L I}^{*}$ & 144 & 242 & $n_{A B W}$ & 574 & $n_{A B W}^{*}$ & 85 & 242 \\
\hline & & & 0.16 & 0.27 & ratio & & & 0.15 & 0.42 \\
\hline \multicolumn{10}{|c|}{$\begin{array}{l}\text { Notes: } r_{j} \text { denotes the top } 10 \text { destinations of each exporting country in } 2005, n_{j} \\
\text { denotes the number of products exported to that destination, } \rho_{r_{j}} \text { denotes the } \\
\text { fraction of goods exported to that destination, out of all goods exported by that } \\
\text { country } n_{i} . n_{j}^{*} \text { represents the expected number of products exported to } j \text { under } \\
\text { independence, while } n_{i}^{*}=\sum_{j} n_{j}^{*} \text { denotes the total number of products exported } \\
\text { to the top } 10 \text { under independence. "Data" shows the number of products to that } \\
\text { destination following a strict pecking order. Finally, "ratio" denotes the fraction } \\
\text { of exported products under independence and in the data respectively. }\end{array}$} \\
\hline
\end{tabular}

Table 1: Pecking order within countries (2005).

\section{From country-specific pecking order to core-periphery in global trade flows}

\subsection{Intuition and tentative evidence}

In the model, the pecking order of destinations for firms inside $i$ is strict since all firms are uniquely identified by $\phi:^{7}$ there exists a cutoff productivity $\phi_{i j}^{*}$ such that all firms for which

7 Eaton et al. (2011) establish a framework where firms inside countries do not strictly follow a pecking order. Around $30 \%$ of French firms follow a strict pecking order in their paper, while the rest of the variation is attributed to firm-destination-level demand shocks. Using simulated method of moments, the authors find that over $50 \%$ of the variance explained by the model can be contributed to a firm's productivity. 
$\phi \geq \phi_{i j}^{*}$ export from $i$ to $j$ and so $T_{i j}=1$ when $\phi_{i}^{\max } \geq \phi_{i j}^{*}$. From (3), profits also vary across destinations as market potential $M P_{i j}$ is varying by $j$. Then it is always possible to rank productivities for firms in $i$ as (Chan and Manova (2015)): $\phi_{i}^{\max } \geq \ldots \geq \phi_{i k}^{*} \geq \phi_{i j}^{*}>\phi_{i i}^{*}$. The most productive firm in $i$ will export to all destinations that $i$ serves, and if a firm exports to the $j+1^{\text {th }}$ most attractive market, it will also export to the $j^{\text {th }}$ most attractive market from this ranking. This pins down $d_{i t}^{\text {out }}$ and the order of opening up to trade for firms inside $i$ in equilibrium. It is also consistent with the skewed distribution of the extensive margin by exporters as in Figure 5, as less productive exporters export to less destinations, while following the same pecking order.

While similar models as Arkolakis et al. (2008), Eaton et al. (2011) or Bernard et al. (2016) all predict a (strict or more loosely) pecking order inside countries, there is no sharp prediction whether all countries follow the same pecking order when choosing destinations: all exporters to $j$ face the same total expenditure $Y_{j}$ and price levels $P_{j}$, but different trade costs $\tau_{i j}$ and $w_{i} f_{i j}$. If the same pecking order strictly holds across exporters, this uniquely pins down the solution to the many-to-many matching problem, the resulting equilibrium quantities and the network structure. In that case, all countries export according to the same pecking order. More formally, if $M P_{i j}$ can be decomposed into bilateral and importer specific elements $M P_{i j}=\left\{\psi_{i j}, \psi_{j}\right\}$, there is a common ranking of exporters among destination countries. ${ }^{8}$ From $M P_{i j} \equiv \frac{Y_{j} P_{j}^{\sigma-1}}{w_{i} f_{i j} \tau_{i j}^{\sigma-1}}$, this is the case whenever $\tau_{i j}=\tau_{j}$ and $w_{i} f_{i j}=w f_{j}$, i.e. trade costs are homogeneous. In that case, for all country pairs $\{i, j\}, M P_{i j}=M P_{j}$ for all $i$, such that market size implies a common ranking of exporters among destination countries, leading to a core-periphery structure in global trade flows.

In the remainder of this section and the next section, we take our model predictions to the data. We first provide tentative evidence for the existence of a core-periphery structure under the assumption of homogeneous trade costs. Next, we relax this assumption and allow for trade costs to differ bilaterally.

Assuming homogeneous trade costs, we look at whether we observe a core-periphery structure in global trade flows, i.e. whether the export ranking of countries is the same for all exporting countries. We deploy the following strategy: first, for each exporter, we rank destinations in

\footnotetext{
8 Helpman et al. (2008) show the conditions for decomposability. In their model, countries have the same general productivity distribution. Either fixed costs are so small that they are not binding for any firm in the world so that all countries export to all other countries. Then the intensity of trade flows only depend on the ex post distribution of productivity draws in each country. In the other case when selection into exporting is binding, if productivities are Pareto distributed and either $\psi_{i j}=\psi_{j}$ or $\psi_{i j}=\psi_{j i}$, the decomposability also holds.
} 
terms of the number of products per trade flow as above, and we keep the top 10 destinations for each exporter in 2005. Second, we generate a global ranking for importers in terms of market potential, again keeping the top 10 importers (see Figure 4 for intuition). We use in-degree $d_{j t}^{i n}$ as a proxy for market potential $M P_{j}$ : if the $j$ level elements dominate the ordering of $M P_{i j}$, we can rank destinations robustly using $j$ characteristics, in this case $d_{j t}^{i n}$. Next, we analyze whether each exporting country follows the same ranking of exporting for this top 10 of destinations and we compare this against a random matching. It turns out that market size indeed implies a common ranking of exporters among destination countries.

Results are presented in Table 2. The first two columns show the top destinations according to their in-degree. The third column calculates the fraction of countries in the world that export to $j$ as $d_{j t}^{i n} / n$. The fourth column shows the number of countries that would follow the same strict pecking order if matching was random. In the fifth column, we compare the random matching to what we find in the data. It is interesting to note that almost all countries export to these top 10 destinations as measured by $d_{j t}^{i n} / n$, so even a random matching generates a very high probability of these 10 countries constituting the core (68\%): it is highly unlikely that a country would only export to the USA and to none of the others in this top 10, just from the number of countries that export to the USA. However, in reality even more exporters follow the same pecking order for this top 10: over $92 \%$ of exporters go down this hierarchical list, hinting that different countries follow the same pecking order. This finding presents tentative evidence that the top 10 countries are equally important for all countries - these countries constitute the core in the world trade network while other countries are part of the periphery.

As alternative measures for market potential, we also use destination GDP, destination GDP per capita, and total imports in 2005 in columns 6 to 8 respectively. There are some differences across the rankings of all measures, which are mostly driven by geographical characteristics (islands, geographical remoteness, and the port of Rotterdam effect for the Netherlands).

\subsection{Gravity-like equation}

The model establishes conditions for (i) a country-specific pecking order of exporters serving their destination countries as well as (ii) a common ranking of exporters among destination countries. Moreover, there is evidence in favor of these findings in the data. We now turn to quantifying the impact of these rankings on bilateral trade flows. First, consistent with the stylized facts in Section 2, we expect that more connected countries export more intensely to 


\begin{tabular}{cccccccc}
\hline Destination & $d_{j t}^{i n}$ & $d_{j t}^{i n} / n$ & $n^{*}$ & data & GDP $($ bio $\$)$ & GDP per capita $(\$)$ & Imports (bio $\$)$ \\
\hline USA & 204 & 0.98 & 0 & 8 & 13,090 & 44,308 & 1,330 \\
GER & 202 & 0.97 & 0 & 32 & 2,860 & 34,650 & 412 \\
GBR & 200 & 0.96 & 0 & 33 & 2,410 & 39,935 & 418 \\
FRA & 199 & 0.96 & 0 & 23 & 2,200 & 34,881 & 398 \\
ITA & 199 & 0.96 & 0 & 49 & 1,850 & 31,973 & 328 \\
NLD & 199 & 0.96 & 0 & 43 & 672 & 41,199 & 275 \\
JPN & 198 & 0.95 & 1 & 3 & 4,570 & 35,781 & 392 \\
KOR & 196 & 0.94 & 1 & 1 & 898 & 18,657 & 233 \\
CAN & 195 & 0.94 & 9 & 0 & 1,160 & 36,029 & 180 \\
POL & 194 & 0.93 & 131 & 0 & 304 & 7,976 & 83 \\
\hline$n$ & 208 & $n^{*}$ & 141 & 192 & & & \\
ratio & & & 0.68 & 0.92 & & &
\end{tabular}

Notes: "Destination" shows the top 10 destinations in terms of in-degree in 2005. $d_{j t}^{\text {in }}$ denotes the in-degree, $d_{j t}^{i n} / n$ denotes the fraction of all countries exporting to $j . n^{*}$ represents the number of countries following a strict pecking order under independence, while "data" denotes the number of countries following a strict pecking order in the data. The last three columns show alternative importer characteristics. "Ratio" denotes the fraction of countries following a strict pecking order under independence and in the data in columns 3 and 4 respectively.

Table 2: Core-periphery in global trade flows (2005).

all of their destinations on average. Second, the model predicts that the impact of the network is mainly through the extensive margin (see (6)). We present a simple gravity-like model that includes our parsimonious measures of $d_{i t}^{o u t}, d_{j t}^{i n}$ and $C_{i t}^{o u t}$, in order to evaluate the impact of market size and trade costs - and therefore the core-periphery setting (measured through network statistics) on bilateral export values.

\subsubsection{Empirical strategy}

Degrees and clustering cannot be directly identified from log-linearizing (7), as these are revealed parameters through the unobservables $\phi$ and $M P_{i j}$. Hence, we propose the following approach to identify our parameters of interest. We regress country-level and bilateral characteristics and $d_{i t}^{o u t}, d_{j t}^{i n}$ and $C_{i t}^{o u t}$ on export values $x_{i j t}$ from $i$ to $j$ in year $t$. In order to account for (unobserved) time-invariant factors, we take a first-differences approach. Additionally, since export flows and network statistics do not vary enormously on a yearly basis, we use the 10-year difference between 1998 and 2008. To account for remaining time-varying components in the same dimension as $d_{i t}^{\text {out }}, d_{j t}^{\text {in }}$ and $C_{i t}^{\text {out }}$, we use typical observable gravity variables. The proposed estimation equation is then:

$$
\Delta \ln x_{i j t}=\alpha_{0}+\alpha^{\prime} \mathbf{X}+\beta_{1} \Delta \ln d_{i t}^{\text {out }}+\beta_{2} \Delta \ln d_{j t}^{\text {in }}+\beta_{3} \Delta \ln C_{i t}^{\text {out }}+\Delta \varepsilon_{i j t}
$$


where $\Delta \ln x_{i j t}=\ln x_{i j 2008}-\ln x_{i j 1998}$ is the approximate percentage growth rate of $x_{i j t}$ from 1998 to $2008, \mathbf{X}$ is a vector of control variables $\left(\Delta \operatorname{lnGDP}_{i t}, \Delta \operatorname{lnGDP}_{j t}, \Delta \mathrm{WTO}_{i t}, \Delta \mathrm{WTO}_{j t}\right.$, $\Delta \mathrm{RTA}_{i j t}$ ), and the coefficients of interest are $\beta_{i}$. Note that using this differences approach forces time-invariant covariates such as the traditional gravity variables of distance, border etc. to drop out.

There is a potential endogeneity issue between changes in the network statistics $\left(\Delta \ln d_{i t}^{\text {out }}\right.$, $\Delta \ln d_{j t}^{i n}$ and $\Delta \ln C_{i t}^{\text {out }}$ ) and changes in export flows, $\Delta \ln x_{i j t}$, as both can be determined simultaneously in (8), and both are also endogenous in the model. Estimating (8) using OLS then leads to biased and inconsistent coefficients. We address this problem by using an instrumental variables (IV) approach. The proposed instruments should be (i) correlated with the endogenous variables, conditional on other covariates, and (ii) uncorrelated with the error term.

We suggest instruments that capture the average of other countries' characteristics, very much in the same spirit as Berry et al. (1995). In particular, as an instrument for $\Delta \ln d_{i t}^{\text {out }}$, we use the average growth rate of out-degrees of all countries except $i: I V\left(\Delta \ln d_{i t}^{\text {out }}\right)=\frac{1}{n-1} \sum_{k \neq i} \Delta \ln d_{k t}^{\text {out }}$. We construct similar instruments for $\Delta \ln d_{j t}^{i n}$ and $\Delta \ln C_{i t}^{o u t}$. The idea is that exports from $i$ to $j$ respond differently to changes in $d_{i t}^{\text {out }}$ compared to changes in the average $\Delta \ln d_{i t}^{\text {out }}$ of all other countries in the world, consistent with the model. Hence, we assume that changes in $I V\left(\Delta \ln d_{i t}^{\text {out }}\right)$ only have an impact on $\Delta \ln x_{i j t}$ through $\Delta \ln d_{i t}^{\text {out }}$, at least at a first-order approximation. The correlation between $\Delta \ln d_{i t}^{\text {out }}$ and $I V\left(\Delta \ln d_{i t}^{\text {out }}\right)$ is 0.95 , while the correlation between $I V\left(\Delta \ln d_{i t}^{\text {out }}\right)$ and $\Delta \ln x_{i j t}$ is 0.21 . The high correlation between the endogenous variables and the instruments can be inferred from the idea that $d_{i t}^{\text {out }}$ evolves in the same direction for all $i$, which is reasonable in the view of increased trade integration and globalization over our sample period. We report both OLS estimates and IV estimates for each specification. Due to potential multi-collinearity of the network variables, we estimate the contribution of each network variable separately.

We use typical gravity data on 182 countries or economic entities in the world for the years 1998 and 2008; GDP and export values $x_{i j t}$ are measured in current US dollars. We also add control variables that are traditionally significant in the gravity model: the Regional Trade Agreement dummy (RTA) has value 1 when both countries have some form of regional trade agreement, including free trade agreements, currency unions etc., and WTO dummies indicate the WTO membership status of the exporter and the importer. Data are described in Appendix A. 


\subsubsection{Total trade}

Table 3 summarizes our regression results. Columns (1)-(2) report the estimates for the regression including $\Delta \ln d_{i t}^{\text {out }}$. The OLS coefficient $\beta_{1}$ is 0.533 and statistically significant at the $0.1 \%$ level. Hence, a growth of $1 \%$ in $d_{i t}^{\text {out }}$ from 1998 to 2008 is related to a $0.5 \%$ increase in export values from $i$ to $j$. Instrumenting $\Delta \ln d_{i t}^{\text {out }}$ leads to very similar results, with an estimated effect of $0.7 \%$. Columns (3)-(4) report the estimates including $\Delta \ln d_{j t}^{i n}$. The OLS estimate is 0.758 and significant, while the IV estimate turns insignificant. In columns (5)-(6), we report the specification including $\Delta \ln C_{i t}^{\text {out }}$. Clustering is negative and statistically significant in both the OLS and IV specifications, with a coefficient around -0.8 . These results confirm our earlier intuition of the role of the network statistics: countries with a high out-degree $d_{i t}^{\text {out }}$ and low clustering $C_{i t}^{\text {out }}$ are in the core of the network and export more to any given destination, while the converse is true for countries in the periphery.

From a completely agnostic point of view, we also test the model specification in two additional ways: (i) VIF tests for multicollinearity of the network statistics and (ii) automatic variable selection using a LASSO and a least angle approach. The VIF tests show that all variance inflation factors remain below 1.2 in all cases, far below typical values of 6-10 for potential multicollinearity issues. The LASSO and least angle approaches show that degrees and clustering are added to the model right after GDP, before the control variables commonly used in gravity estimations.

\subsubsection{Extensive and intensive margins of trade}

Next, we look at the decomposition of the explanatory variables into extensive and intensive margins. The model predicts that the network statistics impact bilateral trade flows through the extensive margin only (see (6). We test this prediction in the data and decompose export values as: $x_{i j t}=n_{i j t} \bar{x}_{i j t}$, where $n_{i j t}$ is the number of products exported from $i$ to $j$ at time $t$ and $\bar{x}_{i j t}$ is the average value of exports per product from $i$ to $j$ at time $t$. The extensive margin coefficients represent the elasticity of the changes in the number of products with respect to trade costs, and similarly the intensive margin coefficients the elasticity of the changes in average shipments. Since this is a decomposition, the estimated coefficients for each margin add up to the estimated coefficients for the total trade specification.

These extra results are presented in Table 4. Columns (1)-(2) report the estimates for the regression on the extensive margin when including $\Delta \ln d_{i t}^{\text {out }}$. The OLS coefficient $\beta_{1}$ is 0.533 , 


\begin{tabular}{|c|c|c|c|c|c|c|}
\hline & $(1)$ & (2) & $(3)$ & (4) & $(5)$ & (6) \\
\hline & OLS & IV & OLS & IV & OLS & IV \\
\hline$\Delta \operatorname{lnGDP}_{i t}$ & $\begin{array}{c}0.596^{* * *} \\
(0.046)\end{array}$ & $\begin{array}{c}0.551^{* * *} \\
(0.076)\end{array}$ & $\begin{array}{c}0.689^{* * *} \\
(0.047)\end{array}$ & $\begin{array}{c}0.617^{* * *} \\
(0.068)\end{array}$ & $\begin{array}{c}0.613^{* * *} \\
(0.047)\end{array}$ & $\begin{array}{c}0.679^{* * *} \\
(0.057)\end{array}$ \\
\hline$\Delta \operatorname{lnGDP}{ }_{j t}$ & $\begin{array}{c}0.762^{* * *} \\
(0.038)\end{array}$ & $\begin{array}{c}0.743^{* * *} \\
(0.060)\end{array}$ & $\begin{array}{c}0.600^{* * *} \\
(0.040)\end{array}$ & $\begin{array}{c}0.705^{* * *} \\
(0.105)\end{array}$ & $\begin{array}{c}0.762^{* * *} \\
(0.038)\end{array}$ & $\begin{array}{c}0.743^{* * *} \\
(0.051)\end{array}$ \\
\hline$\Delta \mathrm{WTO}_{i t}$ & $\begin{array}{c}0.314^{* * *} \\
(0.067)\end{array}$ & $\begin{array}{c}0.054 \\
(0.124)\end{array}$ & $\begin{array}{c}0.398^{* * *} \\
(0.065)\end{array}$ & $\begin{array}{c}0.332^{* * *} \\
(0.089)\end{array}$ & $\begin{array}{c}0.331^{* * *} \\
(0.066)\end{array}$ & $\begin{array}{c}0.483^{* * *} \\
(0.084)\end{array}$ \\
\hline$\Delta \mathrm{WTO}_{j t}$ & $\begin{array}{c}0.289^{* * *} \\
(0.064)\end{array}$ & $\begin{array}{c}0.176 \\
(0.104)\end{array}$ & $\begin{array}{c}0.192^{* *} \\
(0.065)\end{array}$ & $\begin{array}{c}0.427^{* * *} \\
(0.089)\end{array}$ & $\begin{array}{c}0.290^{* * *} \\
(0.064)\end{array}$ & $\begin{array}{c}0.234^{* *} \\
(0.088)\end{array}$ \\
\hline$\Delta \mathrm{RTA}_{i j t}$ & $\begin{array}{c}0.114^{* *} \\
(0.042)\end{array}$ & $\begin{array}{c}0.222^{* * * *} \\
(0.066)\end{array}$ & $\begin{array}{c}0.161^{* * *} \\
(0.043)\end{array}$ & $\begin{array}{c}0.005 \\
(0.090)\end{array}$ & $\begin{array}{l}0.108^{*} \\
(0.042)\end{array}$ & $\begin{array}{c}0.091 \\
(0.060)\end{array}$ \\
\hline$\Delta \ln d_{i t}^{\text {out }}$ & $\begin{array}{c}0.533^{* * *} \\
(0.064)\end{array}$ & $\begin{array}{c}0.660^{* * * *} \\
(0.092)\end{array}$ & & & & \\
\hline$\Delta \ln d_{j t}^{i n}$ & & & $\begin{array}{c}0.758^{* * *} \\
(0.053)\end{array}$ & $\begin{array}{l}-0.092 \\
(0.711)\end{array}$ & & \\
\hline$\Delta \ln C_{i t}^{o u t}$ & & & & & $\begin{array}{c}-0.882^{* * *} \\
(0.092)\end{array}$ & $\begin{array}{c}-0.811^{* * *} \\
(0.133)\end{array}$ \\
\hline Constant & $\begin{array}{l}-0.135^{*} \\
(0.057)\end{array}$ & $\begin{array}{l}-0.152 \\
(0.091)\end{array}$ & $\begin{array}{l}-0.132^{*} \\
(0.056)\end{array}$ & $\begin{array}{c}0.025 \\
(0.139)\end{array}$ & $\begin{array}{c}0.069 \\
(0.057)\end{array}$ & $\begin{array}{l}-0.017 \\
(0.074)\end{array}$ \\
\hline$\overline{R^{2}}$ & 0.0614 & 0.0497 & 0.0685 & 0.0538 & 0.0615 & 0.0728 \\
\hline$N$ & 15,052 & 6,404 & 15,052 & 8,054 & 15,052 & 7,892 \\
\hline
\end{tabular}

Table 3: Gravity estimates, total trade (1998-2008).

identical to the OLS estimate on total trade. Again, instrumenting $\Delta \ln d_{i t}^{\text {out }}$ leads to very similar results, with an estimated effect of $0.7 \%$. Columns (3)-(4) report the estimates on the extensive margin, including $\Delta \ln d_{j t}^{i n}$. The OLS estimate is 0.915 and significant, while the IV estimate turns insignificant. In columns (5)-(6), we report the specification for the extensive margin including $\Delta \ln C_{i t}^{o u t}$. Clustering is negative and statistically significant in both the OLS and IV specifications, with a coefficient around -1 this time. When we turn to the intensive margin, the picture changes completely: all coefficients are insignificant, with the exception of the OLS estimate for $\Delta \ln d_{j t}^{i n}$. To conclude, we find that almost all of the effects of the network statistics are on the extensive margins, in line with the theory above.

\section{Conclusion}

This paper links firm-level productivity and destination market potential (measured through market size and trade costs) to macro observations of country-level trade flows and the network structure of trade at the global level. We argue that these micro decisions generate (i) a country- 


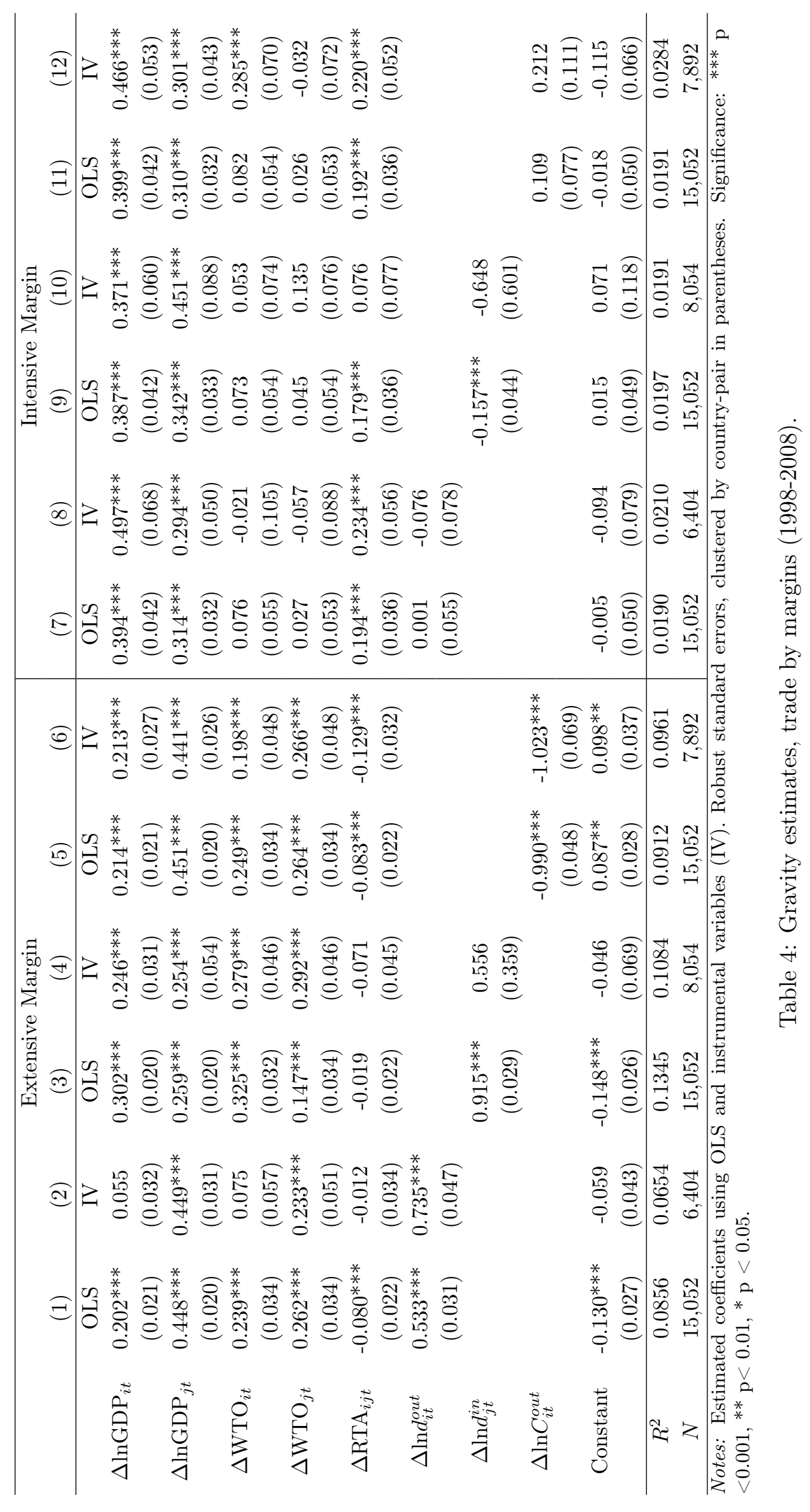


specific pecking order of exporters serving their destination countries and (ii) a core-periphery structure of international trade, in which a core of countries trade heavily among themselves and also with countries in the periphery, while peripheral countries mostly trade with countries in the core. This effect is clearly visible in reality, where highly developed countries mainly occupy the core and developing countries are in the periphery.

In the model, a country-specific pecking order of trade is driven by firm productivity, selfselection into export markets and the market potential of destination markets. If trade costs are homogeneous, market size even implies a common ranking of exporters among destination countries. While the ordering is far from exact in reality, there is substantial evidence in favor of a pecking order mechanism in the data, underlining the role of this mechanism as a substantial force in generating export flows and a global network of trade. Relaxing the unrealistic assumption of homogeneous trade costs, we allow trade costs to differ bilaterally. Taking these heterogeneous trade costs into account, the (joint) impact of trade costs and market size on bilateral trade flows is then quantified (directly) through a simple gravity-like model. Our results show that market size and bilateral trade costs (measured through network indicators) have a strong and significant impact on bilateral trade: countries in the core trade more among themselves than with countries in the periphery. Moreover, these effects are mainly driven by the extensive margin, which is consistent with the model.

These simple findings can raise important policy questions. For instance, if this is the selection mechanism for a core of intensely trading countries, why do some emerging countries move towards the core and others not? There is some evidence on this in Reyes et al. (2010), stating that the degree of openness to trade is important but not enough, and the exact structure of trade for each country matters. Alternatively, Hidalgo et al. (2007) present a framework of creative destruction and the impossibility of countries to bridge particular technological gaps in order to catch up. Understanding the contribution of each channel and the interaction of productivity and market potential can then support policy decisions. For instance, which products to invest in, which destinations to target, and which sources to attract in order to become relatively more integrated in the world trade network. 


\section{References}

Anderson, J. and van Wincoop, E. (2003). Gravity with gravitas: A solution to the border puzzle. American Economic Review, 93(1):170-192.

Antràs, P., Fort, T., and Tintelnot, F. (2016). The margins of global sourcing: Theory and evidence from us firms.

Arkolakis, C., Demidova, S., Klenow, P., and Rodriguez-Clare, A. (2008). Endogenous variety and the gains from trade. American Economic Review: Papers and Proceedings, 98(2):444-450.

Bernard, A., Jensen, B., Redding, S., and Schott, P. (2007). Firms in international trade. Journal of Economic Perspectives, 21(3):105-130.

Bernard, A. B., Moxnes, A., and Ulltveit-Moe, K. (2016). Two-sided heterogeneity and trade.

Berry, S., Levinsohn, J., and Pakes, A. (1995). Automobile prices in market equilibrium. Econometrica, 63(4):841-890.

Chan, J. and Manova, K. (2015). Financial development and the choice of trade partners,. Journal of Development Economics, 116:122-145.

Chaney, T. (2008). Distorted gravity: The intensive and extensive margins of international trade. American Economic Review, 98(4):1707-1721.

Costinot, A. and Rodríguez-Clare, A. (2014). Trade theory with numbers: Quantifying the consequences of globalization. In Gopinath, G., E., H., and Rogoff, K., editors, Handbook of International Economics, Vol. 4. Elsevier.

De Benedictis, L. and Tajoli, L. (2011). The world trade network. The World Economy, 34(8):1417-1454.

Eaton, J. and Kortum, S. (2002). Technology, geography, and trade. Econometrica, 70(5):17411779 .

Eaton, J., Kortum, S., and Kramarz, F. (2011). An anatomy of international trade: Evidence from french firms. Econometrica, 79(5):1453-1498.

Fagiolo, G. (2007). Clustering in complex directed networks. Phys. Rev. E, 76:026107. 
Fagiolo, G., Reyes, J., and Schiavo, S. (2010). The evolution of the world trade web,. Journal of Evolutionary Economics, 20(4):479-514.

Gaulier, G. and Zignago, S. (2010). Baci: International trade database at the product-level. the 1994-2007 version. CEPII Working Paper, 2010-23.

Head, K. and Mayer, T. (2014). Gravity equations: Workhorse,toolkit, and cookbook. In Gopinath, G., Helpman, E., and Rogoff, K., editors, Handbook of International Economics, Vol. 4, pages 131-195. Elsevier.

Helpman, E., Melitz, M., and Rubinstein, Y. (2008). Estimating trade flows: Trading partners and trading volumes. Quarterly Journal of Economics, 123(2):441-487.

Hidalgo, C. A., Klinger, B., Barabasi, A.-L., and Hausmann, R. (2007). The product space conditions the development of nations. Scienc, 317:482-487.

Krugman, P. (1980). Scale economies, product differentiation, and the pattern of trade. American Economic Review, 70(5):950-959.

Melitz, M. (2003). The impact of trade on intra-industry reallocations and aggregate industry productivity. Econometrica, 71(6):1695-1725.

Redding, S. (2011). Theories of heterogeneous firms and trade. Annual Review of Economics, 3:77-105.

Redding, S. and Venables, T. (2004). Economic geography and international inequality. Journal of International Economics, 62(1):53-82.

Reyes, J., Schiavo, S., and Fagiolo, G. (2010). Using complex networks analysis to assess the evolution of international economic integration: The cases of east asia and latin america. The Journal of International Trade and Economic Development, 19(2):215-239.

Santos Silva, J. and Tenreyro, S. (2006). The log of gravity. The Review of Economics and Statistics, 88(4):641-658.

Yeaple, S. R. (2009). Firm heterogeneity and the structure of u.s. multinational activity. Journal of International Economics, 78(2):206-215. 


\section{A Data and Summary Statistics}

Bilateral trade data are obtained from the BACI dataset at CEPII Gaulier and Zignago (2010). ${ }^{9}$ This dataset includes yearly exports at the Harmonized System 6-digit product level (HS6) from a source country to its destination in current US dollars for the years 1998 to 2008. Country characteristics such as GDP are collected from the World Bank. ${ }^{10}$ All monetary variables are expressed in current US dollars. Data on regional trade agreements (RTA) are collected from the website of Jose de Sousa. ${ }^{11}$ This dataset consists of dummy variables equal to one if any RTA was active between any two countries at a given time. WTO membership data has been downloaded from the WTO site. ${ }^{12}$ We calculate the network statistics $d_{i t}^{\text {out }}, d_{j t}^{i n}$ and $C_{i t}^{\text {out }}$ in R. Table 5 shows summary statistics for the year 2005.

\begin{tabular}{cccccc}
\hline Variable & Obs. & Mean & St. dev. & Min & Max \\
\hline Export values $x_{i j t}$ & 39,920 & $2.01 \times 10^{8}$ & $2.37 \times 10^{9}$ & 0 & $1.90 \times 10^{11}$ \\
Number of products $n_{i j t}$ & 39,947 & 138 & 436 & 0 & 4,731 \\
Avg. value per product $\bar{x}_{i j t}$ & 39,947 & 666,655 & $1.01 \times 10^{7}$ & 0 & $1.07 \times 10^{9}$ \\
$R T A_{i j t}$ & 39,947 & 0.07 & 0.3 & 0 & 1 \\
$G D P_{i t}$ & 182 & $2.55 \times 10^{11}$ & $1.10 \times 10^{12}$ & $2.18 \times 10^{7}$ & $1.31 \times 10^{13}$ \\
$W T O_{i t}$ & 208 & 0.7 & 0.5 & 0 & 1 \\
out-degree $d_{i t}^{\text {out }}$ & 208 & 114 & 56 & 6 & 206 \\
in-degree $d_{j t}^{\text {in }}$ & 208 & 114 & 49 & 4 & 204 \\
Clustering $C_{i t}^{\text {out }}$ & 208 & 0.8 & 0.1 & 0.6 & 1 \\
\hline
\end{tabular}

Notes: Monetary values are expressed in current US dollars.

Table 5: Summary statistics (2005).

\footnotetext{
9 http://www.cepii.com/anglaisgraph/bdd/baci.htm

${ }^{10}$ http://data.worldbank.org/indicator/NY.GDP.MKTP.CD

${ }^{11}$ http: //jdesousa.univ.free.fr

12 www.wto.org
} 


\section{B Additional Estimates}

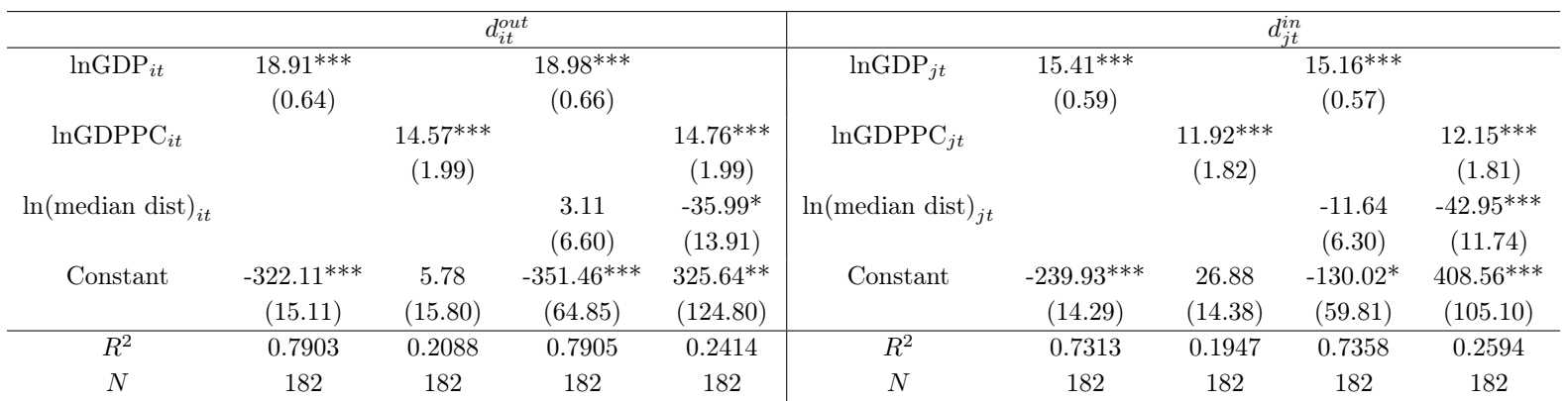

Notes: Robust standard errors between parentheses. GDP and GDP per capita are in current US dollars, and median dist is the median geographical distance of an country to its destinations/sources in km. Significance: *** $\mathrm{p}<0.001,{ }^{* *} \mathrm{p}<0.01,{ }^{*} \mathrm{p}<0.05$.

Table 6: Market size and degrees (2005).

\begin{tabular}{cccc}
\hline & \multicolumn{3}{c}{$C_{i t}^{\text {out }}$} \\
\hline$d_{i t}^{\text {out }}$ & $-0.002^{* * *}$ & & $-0.003^{* * *}$ \\
& $(0.000)$ & & $(0.000)$ \\
$\operatorname{lnGDP}$ & & $-0.044^{* * *}$ & 0.004 \\
& & $(0.002)$ & $(0.003)$ \\
Constant & $1.068^{* * *}$ & $1.833^{* * *}$ & $1.010^{* * *}$ \\
& $(0.007)$ & $(0.047)$ & $(0.050)$ \\
\hline$R^{2}$ & 0.9042 & 0.6931 & 0.9156 \\
$N$ & 208 & 182 & 182
\end{tabular}

Notes: Robust standard errors between parentheses.

Significance: $* * * \mathrm{p}<0.001,{ }^{* *} \mathrm{p}<0.01,{ }^{*} \mathrm{p}<0.05$.

Table 7: Degrees and clustering (2005).

\begin{tabular}{|c|c|c|c|c|c|c|c|}
\hline \multirow{4}{*}{$d_{i t}^{\text {out }}$} & \multirow{2}{*}{$\begin{array}{c}(1) \\
\ln (\text { median variety })_{i t}\end{array}$} & \multirow[t]{2}{*}{ (2) } & (3) & \multirow[t]{2}{*}{ (4) } & \multirow{2}{*}{\multicolumn{2}{|c|}{$\begin{array}{c}(6) \\
\ln (\text { variety })_{i t}\end{array}$}} & \multirow[t]{2}{*}{$(7)$} \\
\hline & & & $(\text { mean variety })_{i t}$ & & & & \\
\hline & $0.028^{* * *}$ & $0.029^{* * *}$ & & $0.020^{* * *}$ & $0.037^{* * *}$ & & $0.025^{* * *}$ \\
\hline & $(0.001)$ & $(0.001)$ & & $(0.002)$ & $(0.000)$ & & $(0.000)$ \\
\hline \multirow{2}{*}{$\ln \mathrm{GDP}_{i t}$} & & & & & $-0.929 * * *$ & $-0.972^{* * *}$ & $-1.003^{* * *}$ \\
\hline & & & & & $(0.011)$ & $(0.012)$ & $(0.012)$ \\
\hline \multirow[t]{2}{*}{$\ln (\text { dist })_{i t}$} & & & $0.591^{* * *}$ & $0.218^{* * *}$ & & $0.755^{* * *}$ & $0.327^{* * *}$ \\
\hline & & & $(0.017)$ & $(0.033)$ & & $(0.004)$ & $(0.008)$ \\
\hline \multirow[t]{2}{*}{ Constant } & $-0.794^{* * *}$ & $0.398^{* * *}$ & $-10.032^{* * *}$ & $-3.683^{* * *}$ & $2.797^{* * *}$ & $-9.735^{* * *}$ & $-2.725^{* * *}$ \\
\hline & $(0.104)$ & $(0.078)$ & $(0.392)$ & $(0.603)$ & $(0.284)$ & $(0.468)$ & $(0.439)$ \\
\hline Importer FE & No & No & No & No & Yes & Yes & Yes \\
\hline$R^{2}$ & 0.8171 & 0.8941 & 0.8217 & 0.9085 & 0.7012 & 0.6887 & 0.7424 \\
\hline$N$ & 208 & 208 & 182 & 182 & 23,760 & 22,514 & 22,514 \\
\hline
\end{tabular}

Notes: Columns (1)-(4) show results for the regressions of mean and median product variety at the exporter level on variables of interest. Columns (5)-(7) consider a bilateral version of product variety at the country-pair level. Products are measured at the Harmonized System 6-digit level (HS6). Robust standard errors in parentheses. Significance: $* * * \mathrm{p}<0.001,{ }^{* *} \mathrm{p}<0.01,{ }^{*} \mathrm{p}<0.05$.

Table 8: Product variety and degrees (2005). 


\section{Model Derivations}

Equilibrium Demand for good $\omega$ produced in $i$ and consumed in $j$ is $q_{i j}(\phi)=\frac{p_{i j}(\phi)^{-\sigma} Y_{j}}{P_{j}^{1-\sigma}}$ and the equilibrium price index of country $j$ is given by the sum of equilibrium prices available for consumption in $j, p_{k j}$, times the density of firms from $k$ serving $j$ conditional on entry in $k, \mu_{k j}$, and finally summing over all active sources $k$ :

$$
P_{j}^{1-\sigma}=\sum_{k: \phi \geq \phi_{k j}^{*}}\left(\int_{0}^{\infty} p_{k j}(\phi)^{1-\sigma} M_{k j} \mu_{k j}(\phi) d \phi\right)
$$

Firms maximize their profits. Given constant markups and bilateral varying fixed costs, the profit maximizing price is an independent problem for each destination $j$ :

$$
\pi_{i j}(\phi)=\max \left\{p_{i j}(\phi) q_{i j}(\phi)-q_{i j}(\phi) \frac{w_{i} \tau_{i j}}{\phi}-w_{i} f_{i j}, 0\right\}
$$

The price of good $\omega$, from $i$ in $j$ is then $p_{i j}(\phi)=\frac{w_{i} \tau_{i j}}{\rho \phi}$. Plugging back into profits and summing over all profitable destinations:

$$
\pi_{i}(\phi)=\sum_{j: \phi \geq \phi_{i j}^{*}} \pi_{i j}(\phi)=\sum_{j: \phi \geq \phi_{i j}^{*}}\left[\left(\frac{\rho \phi P_{j}}{w_{i} \tau_{i j}}\right)^{\sigma-1} \frac{Y_{j}}{\sigma}-w_{i} f_{i j}\right]
$$

Cutoff productivity $\phi_{i j}^{*}$ for firms in $i$ serving $j$ is then given by the zero profit condition for the marginal firm that enters, so that $\pi_{i j}\left(\phi_{i j}^{*}\right)=0$. Setting this condition and simply rearranging:

$$
\phi_{i j}^{*}=\left[\frac{w_{i} f_{i j} \tau_{i j}^{\sigma-1}}{Y_{j} P_{j}^{\sigma-1}} \sigma\left(\frac{w_{i}}{\rho}\right)^{\sigma-1}\right]^{\frac{1}{\sigma-1}}
$$

Equilibrium mass of firms Under free entry, firms enter when they can pay the fixed cost of entry paid in wages, $w_{i} f_{e}$ :

$$
\left[1-G\left(\phi_{i i}^{*}\right)\right] \bar{\pi}_{i}=w_{i} f_{e}
$$


where $\bar{\pi}_{i}$ is the expected profit of firms in $i$ and $G\left(\phi_{i i}^{*}\right)$ is the cumulative distribution function of cutoff productivity to enter the domestic market $i$, which is Pareto distributed:

$$
1-G\left(\phi_{i i}^{*}\right) \equiv\left(\frac{\phi_{\min }}{\phi_{i i}^{*}}\right)^{\theta}
$$

with density $g(\phi)=\frac{\theta \phi_{\min }^{\theta}}{\phi^{\theta+1}}$. Expected profits for firms in $i$ are the linearly separable expected profits for firms, conditional on entry in each market including the home market $i$ :

$$
\bar{\pi}_{i}=\sum_{j: \phi_{i}^{\max } \geq \phi_{i j}^{*}}\left[\frac{1-G\left(\phi_{i j}^{*}\right)}{1-G\left(\phi_{i i}^{*}\right)} \bar{\pi}_{i j}(\phi)\right]
$$

We can also express $\bar{\pi}_{i j}=\int_{\phi_{i j}^{*}}^{\infty} \frac{\pi_{i j}(\phi) g(\phi)}{1-G\left(\phi_{i j}^{*}\right)} d(\phi)$, conditional on entry in $j$. Plugging in these expressions into (13):

$$
\bar{\pi}_{i}=\sum_{j: \phi_{i}^{\max } \geq \phi_{i j}^{*}}\left[\frac{1-G\left(\phi_{i j}^{*}\right)}{1-G\left(\phi_{i i}^{*}\right)} \int_{\phi_{i j}^{*}}^{\infty} \frac{\pi_{i j}(\phi) g(\phi)}{1-G\left(\phi_{i j}^{*}\right)} d(\phi)\right]
$$

Inserting equilibrium profits, $G\left(\phi_{i j}^{*}\right)$ and $g(\phi)$ :

$$
\bar{\pi}_{i}=\sum_{j: \phi_{i}^{\text {max }} \geq \phi_{i j}^{*}}\left[\frac{1-G\left(\phi_{i j}^{*}\right)}{1-G\left(\phi_{i i}^{*}\right)} \int_{\phi_{i j}^{*}}^{\infty} \frac{\left[\left(\frac{\tau_{i j} w_{i}}{\rho \phi P_{j}}\right)^{1-\sigma} \frac{Y_{j}}{\sigma}-w_{i} f_{i j}\right] \frac{\theta \phi_{\min }^{\theta}}{\phi^{\theta+1}}}{\left(\frac{\phi_{\min }}{\phi_{i i}^{*}}\right)^{\theta}} d(\phi)\right]
$$

Rearranging and evaluating the integral:

$$
\bar{\pi}_{i}=\frac{\sigma-1}{\theta-\sigma+1} \sum_{j: \phi_{i}^{\max } \geq \phi_{i j}^{*}} w_{i} f_{i j}\left(\frac{\phi_{i i}^{*}}{\phi_{i j}^{*}}\right)^{\theta}
$$

This allows us to write the free entry condition from (11) as:

$$
\frac{\sigma-1}{\theta-\sigma+1} \sum_{j: \phi_{i}^{\max } \geq \phi_{i j}^{*}} f_{i j}\left(\frac{\phi_{i i}^{*}}{\phi_{i j}^{*}}\right)^{\theta}=\frac{f_{e}}{\left(\phi_{\min } / \phi_{i i}^{*}\right)^{\theta}}
$$

Next, (11) can be expressed as (Redding (2011)):

$$
P_{j}^{1-\sigma}=\sum_{k: \phi_{k}^{\max } \geq \phi_{k j}^{*}} M_{k} \frac{1-G\left(\phi_{k j}^{*}\right)}{1-G\left(\phi_{k k}^{*}\right)} \int_{\phi_{k j}^{*}}^{\infty} p_{k j}^{1-\sigma}(\phi) \frac{g(\phi)}{1-G\left(\phi_{k j}^{*}\right)} d \phi
$$

Plugging in prices, evaluating the integral, using $Y_{j}=w_{j} L_{j}$ and plugging in $\phi_{i j}^{*}$ gives an expres- 
sion for the allocation of labor in $j$ :

$$
L_{j}=\sum_{k: \phi_{k}^{\max } \geq \phi_{k j}^{*}} M_{k}\left(\frac{\phi_{k k}^{*}}{\phi_{k j}^{*}}\right)^{\theta} \frac{w_{k}}{w_{j}} f_{k j} \frac{\sigma \theta}{\theta-\sigma+1}
$$

Now use labor market clearing to determine the mass of firms in $i$. Let $L_{i}=\sum_{j} l_{i j}=l_{i i}+$ $\sum_{j \neq i: \phi_{i}^{\max } \geq \phi_{i j}^{*}} l_{i j}$ be the shares of labor allocated to domestic selling firms $l_{i i}$ and exporters by destination $l_{i j}$. Note that from the cost function $l_{i}=f_{i}+\frac{q_{i}}{\phi}$, it follows that $l_{i j}=f_{i j}+\frac{q_{i} \tau_{i j}}{\phi}$. Now, define variable labor cost for serving market $j$ as $l_{i j}^{v a r}=\frac{q_{j} \tau_{i j}}{\phi}=\frac{p_{i j}^{-\sigma} Y_{j}}{\phi P_{j}^{1-\sigma}} \tau_{i j}$. Then:

$$
L_{i}=M_{i} \frac{f_{e}}{1-G\left(\phi_{i i}^{*}\right)}+M_{i}\left[\sum_{k: \phi_{k}^{\max } \geq \phi_{k j}^{*} \phi_{k j}^{*}} \int_{i k}^{\infty} l_{i k}^{v a r} \frac{1-G\left(\phi_{i k}^{*}\right)}{1-G\left(\phi_{i i}^{*}\right)} \frac{g(\phi)}{1-G\left(\phi_{i k}^{*}\right)} d \phi\right]
$$

Again, evaluating the integral:

$$
L_{i}=M_{i} \frac{f_{e}}{\left(\phi_{\min } / \phi_{i i}^{*}\right)^{\theta}}+M_{i}\left[\sum_{k: \phi_{k}^{\max } \geq \phi_{k j}^{*}}\left(\frac{\phi_{i i}^{*}}{\phi_{i k}^{*}}\right)^{\theta} f_{i k} \frac{(\sigma-1) \theta}{\theta-\sigma+1}\right]
$$

Finally using the cutoff productivities and the free entry condition gives the endogenously determined mass of firms (5):

$$
M_{i}=L_{i} \frac{\left(\phi_{\min } / \phi_{i i}^{*}\right)^{\theta}}{(1+\theta) f_{e}}
$$

Trade flows The value of exports from $i$ to $j$ is given by

$$
X_{i j}=\frac{1-G\left(\phi_{i j}^{*}\right)}{1-G\left(\phi_{i i}^{*}\right)} M_{i} \bar{r}_{i j}
$$

where $\frac{1-G\left(\phi_{i j}^{*}\right)}{1-G\left(\phi_{i i}^{*}\right)}=\left(\frac{\phi_{i i}^{*}}{\phi_{i j}^{*}}\right)^{\theta}$ is the probability of successful exporting to $j$, conditional on successful entry in $i$, and $\bar{r}_{i j}$ is the average revenue for firms in $i$ exporting to $j$ :

$$
\bar{r}_{i j}=\int_{\phi_{i j}^{*}}^{\infty} p_{i j}(\phi) q_{i j}(\phi) \frac{g(\phi)}{1-G\left(\phi_{i j}^{*}\right)} d \phi
$$

Plugging in $p_{i j}$ and $q_{i j}$ and evaluating the integral: 


$$
\bar{r}_{i j}=w_{i} f_{i j} \frac{\sigma \theta}{\theta-\sigma+1}
$$

Plugging back into (15) leads to (6) in the main text:

$$
X_{i j}=T_{i j}\left(\frac{\phi_{i i}^{*}}{\phi_{i j}^{*}}\right)^{\theta} M_{i} w_{i} f_{i j} \frac{\sigma \theta}{\theta-\sigma+1}
$$

To go to the familiar gravity equation (7), we define trade shares as in Arkolakis et al. (2008):

$$
\frac{X_{i j}}{\sum_{k: \phi_{k}^{\max } \geq \phi_{k j}^{*}} X_{k j}}=\frac{T_{i j}\left(\frac{\phi_{i i}^{*}}{\phi_{i j}^{*}}\right)^{\theta} M_{i} w_{i} f_{i j \frac{\sigma \theta}{\theta-\sigma+1}}}{\sum_{k \neq j: \phi_{k}^{\max } \geq \phi_{k j}^{*}}\left(\frac{\phi_{i i}^{*}}{\phi_{i j}^{*}}\right)^{\theta} M_{k} w_{k} f_{k j \frac{\sigma \theta}{\theta-\sigma+1}}}
$$

Plugging in $\phi_{i j}^{*}$ and $M_{i}$ :

$$
\frac{X_{i j}}{\sum_{k: \phi_{k}^{\max } \geq \phi_{k j}^{*}} X_{k j}}=\frac{T_{i j} Y_{i} w_{i} f_{i j}^{1-\theta /(\sigma-1)}\left(w_{i} \tau_{i j}\right)^{-\theta}}{\sum_{k \neq j: \phi_{k}^{\max } \geq \phi_{k j}^{*}} Y_{k} w_{k} f_{k j}^{1-\theta /(\sigma-1)}\left(w_{k} \tau_{k j}\right)^{-\theta}}
$$

Rearranging and using $\sum_{k: \phi_{k}^{\max } \geq \phi_{k j}^{*}} X_{k j}=Y_{j}$ leads to the gravity equation:

$$
X_{i j}=Y_{i} Y_{j} \frac{T_{i j} w_{i} f_{i j}^{1-\theta /(\sigma-1)}\left(w_{i} \tau_{i j}\right)^{-\theta}}{\sum_{k \neq j: \phi_{k}^{m a x} \geq \phi_{k j}^{*}} Y_{k} w_{k} f_{k j}^{1-\theta /(\sigma-1)}\left(w_{k} \tau_{k j}\right)^{-\theta}}
$$

